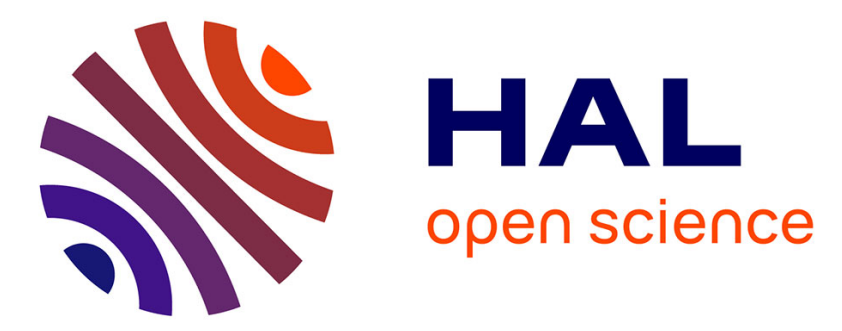

\title{
Krypton storage capacity of the Earth's lower mantle
} A.D. Rosa, Mohamed Ali M.A. Bouhifd, G. Morard, R. Briggs, G. Garbarino, T. Irifune, O. Mathon, S. Pascarelli

\section{To cite this version:}

A.D. Rosa, Mohamed Ali M.A. Bouhifd, G. Morard, R. Briggs, G. Garbarino, et al.. Krypton storage capacity of the Earth's lower mantle. Earth and Planetary Science Letters, 2020, 532, pp.116032. 10.1016/j.epsl.2019.116032 . hal-02453936

\section{HAL Id: hal-02453936 https://hal.uca.fr/hal-02453936}

Submitted on 16 Nov 2020

HAL is a multi-disciplinary open access archive for the deposit and dissemination of scientific research documents, whether they are published or not. The documents may come from teaching and research institutions in France or abroad, or from public or private research centers.
L'archive ouverte pluridisciplinaire HAL, est destinée au dépôt et à la diffusion de documents scientifiques de niveau recherche, publiés ou non, émanant des établissements d'enseignement et de recherche français ou étrangers, des laboratoires publics ou privés. 


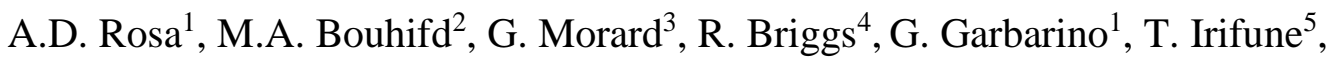
O. Mathon ${ }^{1}$, S. Pascarelli ${ }^{1}$

\section{Abstract}

Noble gases are important geochemical tracers allowing reconstructing global volatile cycles in Earth's reservoirs. To constrain these fundamental processes, precise data on their partitioning behavior at deep Earth conditions are needed. Such data are only available at moderate pressures up to $25 \mathrm{GPa}$ due to experimental challenges. We have investigated the possibility of noble gas storage in the Earth's lower mantle up to $115 \mathrm{GPa}$. We studied the incorporation of krypton in the second most abundant lower mantle mineral $\left(\mathrm{Mg}_{1-\mathrm{x}}, \mathrm{Fe}_{\mathrm{x}}\right) \mathrm{O}$ (ferropericlase) as well as in liquid metal-alloys by performing experiments up to $115 \mathrm{GPa}$ and $3700 \mathrm{~K}$ using the laser-heated diamond anvil cell coupled to post-mortem EMPA analysis and X-ray absorption spectroscopy. The results reveal that, at these extreme conditions, up to 3 wt.\% of krypton can be stored in $\left(\mathrm{Mg}_{1-\mathrm{x}}, \mathrm{Fe}_{\mathrm{x}}\right) \mathrm{O}$ and $3000 \mathrm{ppm}$ in the Fe-rich liquid metal. For both phases the storage capacities increase with pressure (between $40 \mathrm{GPa}$ and $60 \mathrm{GPa}$ ) at a constant high temperature of $2300 \mathrm{~K}$. Fpc has never been considered as a NG host, despite being the second most abundant mineral in the Earth's LM. Using recent accurate 
compressibility data, we demonstrate that a substitution of krypton into the anion site of $\left(\mathrm{Mg}_{1-}\right.$ $\left.{ }_{\mathrm{x}}, \mathrm{Fe}_{\mathrm{x}}\right) \mathrm{O}$ in form of neutral oxygen Schottky defects at diluted lower mantle conditions is possible. This noble gas incorporation mechanism is in agreement with a previous study on bridgmanite. We show that $\left(\mathrm{Mg}_{1-\mathrm{x}}, \mathrm{Fe}_{\mathrm{x}}\right) \mathrm{O}$ exhibits higher noble gas storage capacities than bridgmanite through the lower mantle using lattice strain modelling and including experimental solubility and thermoelastic data for neon, argon, krypton and xenon. We also demonstrate that both phases exhibit the highest solubilities for argon and krypton. We used the solubility data from lattice strain modelling to predict noble gas abundances stored in the solid lower mantle after magma ocean crystallization. The modelled abundances show apparent similarities with estimates for the deep noble gas reservoir that are based on either ${ }^{3} \mathrm{He}$ abundances in ocean island basalts or radiogenic ${ }^{40} \mathrm{Ar}$ abundances in the bulk Earth. This strongly indicates that the crystalline lower mantle may play an important role as deep noble gas storage reservoir. We propose, based on considerations on noble gas replenishment from the lower mantle to the atmosphere, that the lower mantle can only contribute to a small fraction of the present-day atmospheric noble gases. This suggests that the lower mantle is an un-degassed reservoir.

\section{Highlights}

1. Krypton storage capacities of (Mg,Fe)O and metal alloys up to $115 \mathrm{GPa}$ and $3700 \mathrm{~K}$

2. Storage capacities of lower mantle minerals are greater than those of metallic melts

3. Zero-charged krypton is incorporated in neutral oxygen defects of $(\mathrm{Mg}, \mathrm{Fe}) \mathrm{O}$

4. The lower mantle could be a reservoir for noble gases through geologic times 


\section{Introduction}

Noble gases (NGs) are important geochemical tracers allowing reconstructing atmospheric evolution processes over geological time scales (i.e., Moreira, 2013). NG isotope patterns of oceanic island and mid oceanic ridge basalts (OIB and MORB) provide evidence for two different mantle NG reservoirs: the strongly degassed source of MORBs and a less degassed primordial reservoir sampled eventually by deeply originating mantle plumes of OIBs (Allègre and Turcotte, 1986; Marty, 2012; Mukhopadhyay, 2012; Moreira, 2013). The isotopic fingerprints for light $\mathrm{NGs}$ including $\mathrm{He}$ and $\mathrm{Ne}$, indicate that the deep reservoir must have been created very early during Earth accretion (100 Myrs of solar system history) as it retained a fraction of the implanted proto-solar nebula. Moreover, because the deep reservoir inherits a higher fraction of fissogenic non-degassed xenon (Xe) isotopes than MORBs (formed by radioactive decay of $\mathrm{U}$ and $\mathrm{Pu}$ ), it is assumed that the two reservoirs were decoupled early after Earth accretion (about 4.45 Gyrs ago) (e.g., Allègre et al., 1983; Pepin and Porcelli, 2006; Mukhopadhyay, 2012).

The size and location of the deep reservoir still remain subjects of debates because of the difficulties to constrain the exact sources and origins of OIBs. Possible candidates have been proposed including the entire lower mantle (LM), the D', layer and the Earth's core (Allègre and Turcotte, 1986; Marty, 2012; Mukhopadhyay, 2012; Bouhifd et al., 2013; Moreira and Kunz, 2013).

The solubility data of NGs in different deep mantle and core phases (minerals and melts) could provide important information by identifying in which reservoir NGs have preferentially partitioned during the crystallization of the magma ocean (MO). Previous experimental studies on NG solubilities have revealed their preferential partitioning in silicate melts as compared to minerals at upper mantle (UM) conditions (Carroll and Stolper, 1993; 
Matsuda et al., 1993; Brooker et al., 2003; Bouhifd and Jephcoat, 2006; Heber et al., 2007;

Watson et al., 2007). Because NGs exhibit also higher diffusivities in melts than in silicates at shallow mantle conditions (Hofman and Hart, 1978), they are efficiently extracted from the mantle through partial melting and back-recycled into the atmosphere via volcanism.

In contrast to the observed NGs incompatibilities in silicates at shallow mantle conditions, Shcheka and Keppler (2012) reported high compatibilities of argon (Ar) and krypton $(\mathrm{Kr})$ in the LM mineral bridgmanite $(\mathrm{Bg})$. They reported solubilities of up to $1 \mathrm{wt} . \%$ for $\mathrm{Ar}, 3000 \mathrm{ppm}$ for $\mathrm{Kr}$ and $300 \mathrm{ppm}$ for $\mathrm{Xe}$ at $25 \mathrm{GPa}$ and $2100 \mathrm{~K}$ and proposed that NGs are most likely incorporated in neutral oxygen vacancies. Interestingly, Ar solubilities measured in chondritic melts at similar conditions are below those of Bg (Bouhifd and Jephcoat, 2006), while those measured in pure $\mathrm{SiO}_{2}$ melts are in the same order of magnitude $(\sim 1 \mathrm{wt} . \% \mathrm{Ar})$ (Niwa et al., 2013). These discrepancies on NG solubilities in silicate melts might be related to compositional effects. Overall, previous observations suggest that LM minerals may exhibit higher NG solubilities and bear the capacity to store NGs over geological time scales. Shcheka and Keppler (2012) also proposed that the reinjection of these deeply stored NGs, predominantly composed of $\mathrm{Ar}$ and $\mathrm{Kr}$, through mantle melting may explain the Xe depletion signature of the Earth atmosphere (Pepin and Porcelli, 2002). However, the contribution of LM NGs to the present-day atmospheric signature may be only minor as the source of atmospheric xenon has been recently identified to be cometary (about $22 \pm 5 \%$ ), in addition to chondritic (or solar) xenon (Avice et al., 2017; Marty et al., 2017).

In the present study, we provide information on NG storage in LM minerals and melts by investigating experimentally the maximum solubility of $\mathrm{Kr}$ in ferropericlase $(\mathrm{Mg}, \mathrm{Fe}) \mathrm{O}$ and different metal alloys up to the conditions of the bottom of the LM (115 GPa and $3700 \mathrm{~K})$. Our data reveal that ferropericlase can retain up to $3 \mathrm{wt} . \%$ of $\mathrm{Kr}$. This is 5 to 10 times more than Bg in the Earth's LM and metallic melts of the outer Earth's core, respectively. Therefore, we 
propose that ferropericlase may play an important role in NG retention during magma ocean crystallization and that the LM could potentially be a deep NG reservoir.

\section{Methods}

Our experiments are aimed at constraining the $\mathrm{Kr}$ storage capacities of $\mathrm{Fpc}(\mathrm{Mg}, \mathrm{Fe}) \mathrm{O}$ and different metal alloy melts up to the pressure and temperature $(P / T)$ conditions of the bottom of the LM (115 GPa and $3700 \mathrm{~K})$. We have performed laser-heated diamond anvil cell (LH-DAC) experiments at the X-ray absorption (XAS) beamline ID24 of the ESRF. Postmortem EMPA measurements and XAS analysis were used to precisely quantify and characterize the incorporation of NGs in the quenched samples.

\subsection{Starting materials}

We used synthetic metal-alloy foils of $\mathrm{Fe}_{88} \mathrm{~S}_{12}$ and $\mathrm{Fe}_{85} \mathrm{Ni}_{5} \mathrm{~S}_{10}$ which were produced by an ultra-rapid quench method at the ICMPE (Institut de Chimie et des Materiaux de Paris-Est, Paris, France) (Morard et al., 2011). This technique guarantees a void free homogenous composition and a small sample thickness $(5-7 \mu \mathrm{m})$. Nickel foils from Goodfellow (trace element basis 99.95\%), $\mathrm{MgO}$ powder from Sigma Aldrich (catalogue number: 34279) and $\mathrm{Kr}$ gas having a purity of $99.99 \%$ from Air Products were used as high-purity starting materials. The $\mathrm{MgO}$ powder was heated above $393 \mathrm{~K}$ to remove the moisture contamination from the air. After heating, it was compressed under nitrogen atmosphere to produce thin pellets of 5-10 $\mu \mathrm{m}$ thickness using a diamond anvil cell without gasket. In such a device, the $\mathrm{MgO}$ powder is subjected to a high-pressure sintering process (up to $10 \mathrm{GPa}$ ) which leads to a highly compacted material with a very low porosity. The resulting metal foils and $\mathrm{MgO}$ pellets were stored in a dry atmosphere before sample loading.

\subsection{High pressure and temperature experiments}



generate high pressures. The DACs were equipped with single-crystal or nano-polycrystalline diamonds. The dimensions of diamond anvil culets varied between 150 and $400 \mu \mathrm{m}$ depending on the target pressure (40-115 GPa). For all experiments, we have employed pre-indented Re gaskets. A hole drilled at the center of the gasket was used as sample chamber (Table 1).

In total seven samples were prepared and investigated (Table 1). Two samples were prepared using a $5 \mu \mathrm{m}$ thick metal foil of $\mathrm{Fe}_{88} \mathrm{~S}_{12}$ sandwiched between two $\mathrm{MgO}$ pellets 
(Figure 1). The metal foils placed only on a $\mathrm{KCl}$ disk were heated on the metal(-alloy) contact surface to $\mathrm{Kr}$ in several positions. The laser hot-spot diameter varied between 20 and $60 \mu \mathrm{m}$ depending on the sample size and pressure. The temperature was raised up to 1800-3700(150) $\mathrm{K}$ by adjusting the laser power and maintained for 20-30 minutes to reach equilibrium conditions.

At the $P / T$ conditions of the experiments, $\mathrm{Kr}$ and $\mathrm{MgO}$ remained solid (Jephcoat, 1998; Du and Lee, 2014). This excludes the formation of supercritical $\mathrm{Kr}$ or $\mathrm{Kr}$ gas during the experimental runs. In contrast, the experimental temperatures exceeded by several hundred degrees the liquidus temperature of metal foils (except for the heating spot 2 in Cell_7) (Morard et al., 2008, 2011; Lord et al., 2014; Mori et al., 2017).

\subsection{Elemental concentration measurements}

Scanning electron microscope (SEM) maps of recovered samples were acquired with a small beam size of $2 \mu \mathrm{m}$ and at an acceleration voltage of $20 \mathrm{kV}$, except for Cell_7, to determine the distribution of $\mathrm{Fe}, \mathrm{Si}, \mathrm{O}, \mathrm{S}, \mathrm{Mg}$ and $\mathrm{Ni}$, using the SEM microscope installed at the 
moved were discarded. Measurements with analytical totals within $95 \%$ were included in the analysis in addition to few data with totals above $85 \%$. Measurements with totals below $85 \%$ were excluded.

In two cases, the EMPA measurements of the laser-heated iron-alloy areas resulted in surface structure changes due to the impinging electron beam. This effect is most likely related to sample disproportions linked to the metastable nature of the quenched glasses. We therefore discarded these measurements. All Kr concentrations obtained from EMPA measurements in the samples and different phases are listed in Table S1, except for Cell_5 for which the measured concentrations fell below the detection limit and Cell_7 for which EMPA measurements have not been performed.

\subsection{XRF and XAS experiments}

$\mathrm{X}$-ray absorption spectroscopy (XAS) is a powerful technique to probe the local structural environment of diluted elements embedded in crystalline or glass matrixes. XAS data acquired in transmission geometry present the sum of all contributions along the beam pathway. In the present study, the sample configuration was optimized to separate the signal from pure krypton loaded in the sample chamber cavity next to $\mathrm{MgO}$ and the one from the krypton incorporated in the crystal after laser-heating (Figure 1). At ID24 in-situ XAS transmission measurements on $\mathrm{Kr}$ retained in the oxide during heating were unfortunately not possible due to the low concentrations of $\mathrm{Kr}$ retained in the laser-heated hotspot and the large $\mathrm{X}$-ray beam size at the $\mathrm{Kr} \mathrm{K}$-edge $(50 \mu \mathrm{m}$ at full width half maximum) which exceeded the laser hotspot size (Figure 1).

A much smaller beamsize (submicron) than presently available is required to conduct such experiments in-situ during heating or after heating and at high pressure. Therefore, only XAS data of pure $\mathrm{Kr}$ upon compression and after heating could be collected at ID24. The 
structural environments around $\mathrm{Kr}$ retained in the heating spot were therefore investigated only on quenched samples by XAS. These measurements were conducted in backscattered fluorescence geometry at the ESRF beamline BM23 using a highly focused beam of $5 \times 5 \mu \mathrm{m}^{2}$ (Supplementary Information). The measurements were completed by full-multiple scattering calculations to derive the atomic environments around $\mathrm{Kr}$ in the quenched samples (Supplementary Information).

\section{Results and discussion}

\section{1 $\mathrm{Kr}$ concentrations retained in Fpc and metallic melts}

Detailed elemental concentrations obtained from EMPA measurements for each sample are listed in Table S1. For Cell_1-2, we observed that laser-heating of pure MgO in contact with the $\mathrm{Fe}_{88} \mathrm{~S}_{12}$ alloy resulted in the diffusion of $\mathrm{Fe}$ into $\mathrm{MgO}$ forming Ferropericlase $\left(\mathrm{Mg}_{1-}\right.$ $\left.{ }_{x}, \mathrm{Fe}_{\mathrm{x}}\right) \mathrm{O}$ with $\mathrm{x}$ reaching up to 0.27 . In the following, the resulting $\left(\mathrm{Mg}_{1-\mathrm{x}}, \mathrm{Fe}_{\mathrm{x}}\right) \mathrm{O}$ phase will be referred to as Fpc.

The EMPA measurements and the XRF and SEM maps revealed that $\mathrm{Kr}$ concentrations in Fpc and the metal foils show variations with the distance from the laser hotspot (Figure 2 and S1, Cell_1, 2 and 6). Interestingly, the Kr contents measured for Fpc samples show a slight decrease with increasing distance from the hotspot (within a diameter of $20 \mu \mathrm{m}$ ). The observed concentration variations may be related to a partitioning or diffusion process that is sensitive to the temperature decrease with increasing distance from the laser hotspot.

Lateral temperature gradients in the LH-DAC depend on the laser beam shape, as well as the thermal conductivity of the sample and insulating material. We have maximized the laser-heating spot in all experiments in order to reduce the thermal gradients in its center and maximize the area where the concentration measurements were carried out. The measurement 
of the thermal gradients across the laser hotspot requires special LH-DAC setups (Campbell, 2008). The present measurements have been performed on a standard system that does not allow such measurements. We therefore assumed temperature gradients between 500-1200 K from the hotspot center to the hot-spot rim for measured hotspot temperatures ranging from $2300-3700 \mathrm{~K}$ following the observations of Campbell (2008) and Fischer et al. (2015). Due to the micrometric size of the samples, submicron beams would be necessary to better explore the effect of temperature gradients on $\mathrm{Kr}$ concentration variations. Such micro-beams are presently not available for standard EMPA instruments.

First order constrains on the relations between temperature, pressure as well as chemical composition and measured $\mathrm{Kr}$ contents in the different phases can be obtained by averaging those $\mathrm{Kr}$ concentrations measured in the hotspot center (within a diameter of $20 \mu \mathrm{m}$ ) and laserheating spot rim (within a diameter of $20-40 \mu \mathrm{m}$ ). This procedure allows separating regions in the laser hotspot that exhibit the most homogeneous temperature distributions from those that are subjected to higher $\mathrm{T}$ gradients. The $P / T$ conditions of each cell and laser-heated spot together with the resulting averaged $\mathrm{Kr}$ concentrations of phases at different distances from the laser hotspot are listed in Table 1 together with the maximal $\mathrm{Kr}$ concentrations measured in each sample and averaged $\mathrm{Kr}$ concentrations using all measurements.

The $\mathrm{Kr}$ concentrations measured in Fpc in the hotspot center as a function of the pressure, the iron and sulfur content are shown in Figure 3. The most striking observations are the high $\mathrm{Kr}$ concentrations of almost 3 wt.\% in Fpc (Table 1, Cell_2) and their increase with pressure (Figure 3). We also found that $\mathrm{Kr}$ concentrations in Fpc are strongly correlated with the Fe content (Figure 3a, taking only the data from the hotspot center). With increasing pressure from 40 to $60 \mathrm{GPa}$ the average $\mathrm{Kr}$ and $\mathrm{Fe}$ contents in Fpc increases from 1.2(2) to 2.2(5) wt.\% and 7(3) to 23(4) wt.\%, respectively (Figure 3a). For sulfur, we observed the 
opposite trend: the averaged sulfur concentrations in Fpc are slightly higher at $40 \mathrm{GPa}$ than at $60 \mathrm{GPa}$, decreasing from 2.1(4) down to 0.15(5) wt.\% (Figure 3b).

We observed the highest $\mathrm{Fe}$ and $\mathrm{Kr}$ concentrations in the center of the laser heated hotspot in Fpc. This excludes a diffusion activated by the thermal gradients (Soret effect) which should normally result in a migration of heavy elements such as $\mathrm{Fe}$ or $\mathrm{Kr}$ towards the hotspot rim (Auzende et al., 2008). We considered instead that equilibrium conditions have been achieved during the long laser heating runs at least for Fe in the hotspot center (Auzende et al., 2008). To understand if the equilibrium conditions for $\mathrm{Kr}$ in the entire heating spot (max. 60 microns at $40 \mathrm{GPa}$ ) were also reached, the diffusion coefficients for $\mathrm{Kr}\left(\mathrm{D}_{\mathrm{Kr}}\right)$ in Fpc at the present experimental conditions are required. These coefficients are however not available. We therefore related the concentration variations of $\mathrm{Fe}$ and $\mathrm{Kr}$ in the hotspot center in Fpc to the temperature dependent partitioning behavior of $\mathrm{Fe}$ and $\mathrm{Kr}$ into Fpc.

$\mathrm{Kr}$ concentrations in quenched metallic melts as a function of the $P / T$ conditions, distance to the laser-heated hotspot and composition are plotted in Figure 4. Molten Ni shows the highest $\mathrm{Kr}$ storage capacity, among all investigated metallic melts. It could retain a maximum of $0.77(1)$ wt.\% of $\mathrm{Kr}$ at $62(1) \mathrm{GPa}$ and $2800 \mathrm{~K}$ (Table 1). This value is much larger than for $\mathrm{Fe}_{88} \mathrm{~S}_{12}$ and $\mathrm{Fe}_{85} \mathrm{~N}_{5} \mathrm{~S} \mathrm{~S}_{10}$ which respectively exhibit a maximum of $0.38(1)$ and $0.14(1)$ wt.\% at similar conditions (Table 1). Interestingly, the averaged $\mathrm{Kr}$ storage capacities of the metallic melts are much lower than those of Fpc (Figure 3). Moreover, we did not observe a correlation between the $\mathrm{Kr}$ and $\mathrm{S}$ contents in $\mathrm{Fe}_{88} \mathrm{~S}_{12}$ as in Fpc (Table S1). 


\subsection{Kr partitioning in the lower Earth's mantle}

In-situ experiments at the relevant high dilution levels and extreme conditions remain

261

262

challenging. The present experiments have been performed at $\mathrm{Kr}$-saturated conditions similar to previous large-volume press studies on Bg (Shcheka and Keppler, 2012) or LH-DAC studies on silicate melts (Chamorro-Perez et al., 1996; Bouhifd and Jephcoat, 2006; Bouhifd et al., 2013; Niwa et al., 2013). The derived concentrations in quenched samples of such studies present the upper limit of $\mathrm{Kr}$ solubilities in the different phases (Table 1).

We averaged the $\mathrm{Kr}$ concentrations from all EMPA measurements within the laserheated spot in each phase at a certain $P / T$ point to estimate the maximum $\mathrm{Kr}$ solubilities as a function of pressure in the different phases (Table 1, column named: everything). We considered that this procedure provides a better statistical measure of $\mathrm{Kr}$ retained in the laser hotspot. The resulting maximal $\mathrm{Kr}$ solubilities in Fpc are 1.2 and 1.8 wt.\% and 0.03 wt.\% and 0.15 wt. $\%$ for $\mathrm{Fe}_{88} \mathrm{~S}_{12}$ at 40 and $60 \mathrm{GPa}$ and $2300 \mathrm{~K}$, respectively. These estimated $\mathrm{Kr}$ solubilities are presented in Figure 5a and were used to assess the pressure dependent partitioning coefficients $\mathrm{D}_{\text {metal/oxide }}$ shown in Figure 5b (black triangles). The resulting $\mathrm{D}_{\text {metal/oxide }}$ values are below unity indicating that $\mathrm{Kr}$ preferentially partitions into Fpc. An extrapolation of $\mathrm{D}_{\text {metal/oxide }}$ to the core mantle boundary reveals, that the preference for $\mathrm{Kr}$ to enter into Fpc prevails, while small amounts of $\mathrm{Kr}$ may still be present in the Earth's core.

The present results indicate that $\mathrm{Kr}$ is highly soluble in Fpc and to a lesser extent in metallic melts. The liquid Earth's core as well as liquid iron droplets descending within the magma ocean during Earth's core formation would therefore be rather poor in $\operatorname{Kr}$ (Figure 5). Our data suggest that for both Fpc and metallic melts the solubility increases with depth. These observations strongly differ from the previously reported Ar solubility decrease in silicate melts beyond $15 \mathrm{GPa}$ (i.e., Bouhifd and Jephcoat, 2006; Niwa et al., 2013). According to Bouhifd 
and Jephcoat (2006), the Ar solubility in chondritic melts reduces at $25 \mathrm{GPa}$ to $0.05 \mathrm{wt} . \%$. This

284

285

286

287

is a factor of 10 less than what we estimated for $\mathrm{Kr}$ in Fpc at such conditions (0.56 wt.\% at 25 GPa). The extrapolation of the data from Niwa et al. (2013) in pure silicate beyond $20 \mathrm{GPa}$ suggests an Ar solubility of $1 \mathrm{wt} . \%$ at $25 \mathrm{GPa}$ and a decrease to $0.5 \mathrm{wt} . \%$ at $30 \mathrm{GPa}$. These observations may indicate that $\mathrm{Kr}$ is retained in crystalline phases especially at the bottom of the Earth's LM during mantle crystallization. This is due to the probable incompatibility of NGs in ultra-dense silicate melts. The solubilities in melts remain however still debated due to the few studies conducted so far. Therefore, a more elaborated discussion on crystal-melt partitioning behavior at LM conditions is not warranted.

Shcheka and Keppler (2012) reported $\mathrm{Kr}$ solubilities in Fe-free and Al-bearing bridgmanite from 0.11 to 0.33 wt. $\%$ at $25 \mathrm{GPa}$ and $1800 \mathrm{~K}$ that increase with the $\mathrm{Al}$ content. Using their data, we obtained a partitioning coefficient between bridgmanite (Brg) and Fpc $\mathrm{D}_{\mathrm{Fpc} / \mathrm{Brg}}$ of 1.69 to 4.9 (9) at $~ 25 \mathrm{GPa}$. We found that Fpc can retain a maximum of $3.5 \mathrm{wt} . \%$ of $\mathrm{Kr}$ (Figure 5a) by extrapolating the maximal solubility of $\mathrm{Kr}$ in $\mathrm{Fpc}$ to the CMB. The lower storage capacity of $\mathrm{Bg}$ might be due to the absence of iron in the experiments of Shcheka and Keppler (2012). Iron could indeed play an important role for forming oxygen vacancies. Future studies on NG incorporation in iron-bearing bridgmanite are required to better understand partitioning of NGs between the two main crystalline constituents of the Earth's LM. Overall, Fpc exhibits a higher $\mathrm{Kr}$ solubility than $\mathrm{Bg}$ and despite Fpc is volumetrically inferior (Fpc:Bg $=20: 80$ vol. $\%$ ), it can store up to $45 \%$ of the $\mathrm{Kr}$ present in the LM. 


\subsection{Kr incorporation mechanism}

The understanding of the microscopic NGs incorporation mechanism in LM solid and liquid phases is fundamental for predicting their partitioning behaviors (Karato, 2016). However, this mechanism remains largely unexplored except for Bg (Shcheka and Keppler, 2012). At moderate $P / T$ conditions, NGs can substitute in open ring structures of hydrous phases (Jackson et al., 2013), or cation positions in silicates (Heber et al., 2007). Because pure Kr exhibits a high compressibility (Rosa et al., 2018), it may also be easily stored in defect vacancies or interstitial sites of phases present at Earth's LM and core conditions.

We calculated the size mismatch between atomic radii of zero charged $\mathrm{Kr}^{0}, \mathrm{Mg}^{2+}, \mathrm{O}^{2-}$ and metallic $\mathrm{Fe}$ at $2300 \mathrm{~K}$ and between 40 and $150 \mathrm{GPa}$ (Figure 6, Supplementary Information) to understand if $\mathrm{Kr}$ atoms at Earth's $\mathrm{LM}$ conditions can fill vacancies or substitute for atoms in Fpc and/or metallic melts. Interestingly, the size mismatch between $\mathrm{Kr}^{0}$ and the $\mathrm{O}^{2-}$ anion in Fpc is the lowest and remains below 10\% (Figure 6b). This indicates that at diluted concentrations of the $\mathrm{LM}, \mathrm{Kr}^{0}$ can be incorporated into a neutral oxygen vacancy such as a Schottky defect. The size mismatch between $\mathrm{Kr}^{0}$ and $\mathrm{O}^{2-}$ decreases with increasing pressure (Figure 6b). The proposed substitution of $\mathrm{Kr}$ in neutral oxygen Schottky defects can therefore explain the observed increase in solubility (Figure 3). It can also explain the increasing compatibility of $\mathrm{Kr}$ in Fpc with increasing iron content. In Fpc such neutral oxygen vacancies could be preferentially associated to iron defect clusters forming, upon increasing pressure, iron and $\mathrm{Fe}^{3+}$ content (Kantor et al., 2009).

If $\mathrm{Kr}$ solubility in $\mathrm{Fpc}$ is associated to the abundance of $\mathrm{Fe}^{3+}$ related vacancies, then solubilities should be sensitive to the oxygen fugacity $\left(\mathrm{fO}_{2}\right)$. In the present experiments, the $\mathrm{fO}_{2}$ can be estimated relatively to the iron-wüstite buffer (IW buffer) using the molar fractions 
of $\mathrm{Fe}$ in the metal phase and $\mathrm{FeO}$ in the mineral phase obtained from EMPA measurements

(Table S1). We considered an ideal system and calculated $\mathrm{fO}_{2}$ using the equation:

$$
\log \mathrm{fO}_{2}(\Delta \mathrm{IW})=2 \log \left(\mathrm{XFeO} O_{\text {silicate }} / \mathrm{XFe} e_{\text {metal }}\right)
$$

where $\mathrm{XFeO}$ mineral and $\mathrm{XFe} e_{\text {metal }}$ are the molar fractions of $\mathrm{FeO}$ and $\mathrm{Fe}$ in the mineral and metallic phases, respectively. We have obtained $\operatorname{logfO}_{2}$ values ranging from $-2.1(3)$ to $1.5(2)$ at pressures between 40 to $60 \mathrm{GPa}$ and $2300 \mathrm{~K}$. These values are consistent with those obtained in previous works conducted at comparable conditions (Fischer et al., 2015) and can explain the observed correlation of $\mathrm{Kr}$ solubility increase with $\mathrm{Fe}^{3+}$ abundance. The redox conditions for the accreting mantle have been estimated to range between 4 and $2 \log$ units below the IW buffer (Rubie et al., 2011). This confirms that the present experiments have been conducted at similar or slightly more oxidizing conditions than those of the early Earth.

Recently, an incorporation of single $\mathrm{Kr}$ atoms in neutral Schottky defects associated with oxygen vacancies has been also evidenced from XAS measurements of $\mathrm{Kr}$-implanted $\mathrm{UO}_{2}$ for low $\mathrm{Kr}$ concentrations of 0.5 at.\% and at ambient conditions (Martin et al., 2015). Oxygen vacancy substitution has been also proposed for the incorporation of $\mathrm{Ar}, \mathrm{Kr}$ and $\mathrm{Xe}$ in $\mathrm{Bg}$ based on lattice strain modelling (Shcheka and Keppler, 2012; Karato, 2016).

For molten $\mathrm{Fe}_{88} \mathrm{~S}_{12}$ our calculations have revealed a large radii mismatch between $\mathrm{Fe}^{0}$ and $\mathrm{Kr}^{0}$ in the pressure range of $60-150 \mathrm{GPa}$, with $\mathrm{Kr}$ being $30 \%$ smaller than $\mathrm{Fe}^{0}$ (Figure $6 \mathbf{b}$ ). We propose that $\mathrm{Kr}$ is entrapped in interstitial voids of the metallic liquid structure because of the likely $\mathrm{Kr}$ diffusion in the low viscous metallic melt. Such an interstitial diffusion mechanism is consistent with the general concept of NG incorporation in silicate melts (Caroll and Stolper, 1993; Brooker et al., 2003; Heber et al., 2007). Detailed atomistic crystal and melt lattice calculations, that are beyond the scope of the present study, are required to better 
constrain the potential incorporation sites of NGs in these systems at lower Earth's mantle conditions.

\subsection{Local atomic environment of $\mathrm{Kr}$ in quenched samples}

The present study is the first attempt to characterize the incorporation mechanism of NGs in quenched LM minerals directly using XAS (Supplementary Information). The extended X-ray absorption fine structure (EXAFS) which corresponds to the X-ray energy domain located $1000 \mathrm{eV}$ above the absorption edge, is highly sensitive to the distribution and sort of nearest-neighboring atoms. EXAFS data collected at the $\mathrm{Kr} \mathrm{K}$-edge demonstrate the existence of a highly disordered first coordination shell that is characterized by a large distribution of inter-atomic distances and different coordinating atomic species including $\mathrm{Kr}$, Fe or Mg (Figure S3). The X-ray absorption near edge structure (XANES) which corresponds to the energy region that extends $\sim 100 \mathrm{eV}$ from the absorption edge, provides information on the local site symmetry of the absorbing atom and sort of neighbouring atoms on the medium range scale (second and third coordination shells). A clear similarity between the spectra of $\mathrm{Kr}$ retained in quenched samples and those of liquid and solid krypton is apparent (Figure S4). This suggests that $\mathrm{Kr}$ could partly have, as nearest neighbor, another $\mathrm{Kr}$ atom with a similar symmetrical arrangement as pure liquid or solid fcc $\mathrm{Kr}$ under pressure. A comparison of the experimental and calculated XANES spectra shows that $\mathrm{Kr}$ is most likely incorporated in 6fold coordinated vacancies surrounded by $\mathrm{Fe}$, and $\mathrm{Mg}$ as next nearest neighbors (Figure S45). The potential substitution of $\mathrm{Mg}$ or $\mathrm{Fe}$ by $\mathrm{Kr}$ is a very unlikely scenario because, in this case, the calculated XANES spectra exhibit a significantly different shape of the white line (Figure S5). The local environment of $\mathrm{Kr}$ in quenched Fpc is disordered and composed of $\mathrm{Mg}$, $\mathrm{Fe}$ and $\mathrm{Kr}$ with various amounts as nearest neighbors. The shift of the white line energy in the sample spectra relatively to those of $\mathrm{Kr}$ gas clearly demonstrates that $\mathrm{Kr}$ is retained under 

Information).

An explanation for the observed highly distorted $\mathrm{Kr}$ environments could be the significant expansion of the previously homogeneously distributed $\mathrm{Kr}$ atoms during $P / T$ quenching. Quenching from $40 \mathrm{GPa}$ leads to a volume expansion of more than $50 \%$ for $\mathrm{Kr}$ (Rosa et al., 2018) resulting in the generation of large lattice strains in the host sites. These lattice strains can induce short range diffusion of $\mathrm{Kr}$ and lattice re-arrangement leading to the formation of defect clusters of sub-nanometric size. This type of cluster formation has been already reported for implanted samples such as MgO (Norton et al., 1992; Noordhuis and De Hosson, 1991). We do not consider that hydrous fluid inclusions containing $\mathrm{Kr}$ have formed in our samples. As outlined above in the methods section, we have employed pre-heated $\mathrm{MgO}$ powder as well as metal foils stored under vacuum in a desiccator to avoid moisture contamination. In addition, the sample was assembled and sealed in nitrogen atmosphere before loading with $\mathrm{Kr}$ in a gas-loading device.

We consider that it is very unlikely that $\mathrm{Kr}$ was substantially trapped on grain boundaries between $(\mathrm{Mg}, \mathrm{Fe}) \mathrm{O}$ crystals during the experiments, as we have employed precompressed (dried, water-free) $\mathrm{MgO}$ pellets. These pellets were made from a $\mathrm{MgO}$ powder that was highly compacted in a DAC. In such device, the $\mathrm{MgO}$ powder is subjected to a high pressure sintering process (up to $10 \mathrm{GPa}$ ) which leads to a highly densified material with low to negligible porosity. Also, similar XAS data of $\mathrm{Kr}$ were obtained with samples prepared using a very different synthesis method. Indeed, the iron-alloy foils have been obtained using sputtering methods, a technique that leads to compact foils without voids. Moreover, grain boundary contamination or formation of $\mathrm{Kr}$ blebs would lead to constant $\mathrm{Kr}$ concentrations in the samples independently of the experimental conditions while we observe an increase of the 
$\mathrm{Kr}$ concentrations with pressure that is consistent with the predictions of Shcheka and Keppler (2012).

TEM measurements could provide information about the $\mathrm{Kr}$ environment in the quenched samples. Such studies on $\mathrm{Kr}$ contained in $\mathrm{MgO}$ have been previously performed on thin ion-implanted $\mathrm{MgO}$ discs that did not require polishing (Norton et al., 1992). The samples produced in the present study would however require polishing due to the underlying iron foil.

We did not perform such measurements because this type of polishing procedure would lead to NG release. In addition, TEM measurements can be only performed on quenched samples that are altered by the significant expansion of $\mathrm{Kr}$ once released to room pressure (Tan et al., 1991; Norton et al., 1992; Martin et al., 2015).

In summary, based on the atomic radii mismatch calculations, we find that $\mathrm{Kr}$ incorporated in Fcp via a vacancy substitution mechanism at high $P / T$ conditions is possible. Moreover, as $\mathrm{Kr}$ remains solid at the high $P / T$ conditions of the experiments and the starting materials employed are void free due to the pre-compressing treatment or used synthesis methods, it is unlikely that $\mathrm{Kr}$ blebs form inside Fpc and the metallic foils. The formation of $\mathrm{Kr}$ blebs at the surface of Fpc and the metallic foils can be excluded because the experimental XANES spectra clearly demonstrate that $\mathrm{Kr}$ is retained under a high compressive stress of up to 8 GPa (Figure S4, S6) that can only be sustained in the bulk and not on the surface of the samples. Therefore, we propose that the observed $\mathrm{Kr}$ concentrations are due to diffusion processes that took place at high $P / T$ conditions. The precipitation of NG nano-impurity clusters related to $\mathrm{Kr}$ exsolution are induced during quenching. We note that sub-nanometric $\mathrm{Kr}$ clusters potentially formed in the quenched samples have a minor influence on the conducted EMPA measurements. The electron beam size for EMPA measurements was in the range of $2 \mu \mathrm{m}$. Therefore, the sampling was conducted on several sub-(nanometric) impurity clusters as well as on cluster free-areas during one measurement. 


\section{Implications}

425

426

427

428

429

430

431

432

433

434

435

436

437

438

439

440

441

442

443

444

445

446

\subsection{NGs solubilities in the lower mantle minerals}

The present experimental results reveal that Fpc can retain 5 times more $\mathrm{Kr}$ than $\mathrm{Fe}$ free and Al-bearing Bg in the Earth's uppermost LM and 10 times more than the liquid Earth's outer core. Our results suggest that a larger proportion of the mantle's $\mathrm{Kr}$ is stored by Fpc than previously thought. In order to constrain the solubilities of $\mathrm{Ne}, \mathrm{Ar}, \mathrm{Kr}$ and $\mathrm{Xe}$ through the $\mathrm{LM}$ (25-120 GPa and 1900-2500 K), we performed lattice strain modelling (LSM) (Blundy and Wood, 2003) assuming that NGs enter in neutral oxygen vacancies of Fpc and Bg.

This LSM allowed us predicting solubilities through the mantle for the suite of NGs.

NGs exhibit high compressibilities and it is therefore important to include their volumetric variations through the LM. The coordination number is another parameter that has a significant influence on the host site and noble gas radii (Zhang and Zhu, 1995). In the present LSM approach, the radii of NGs and those of the host sites were fixed to calculated values obtained using thermoelastic and crystal-chemistry data (coordination dependent atomic radii size). Similarly, the host site flexibility was fixed to the calculated values extracted from thermoelastic data (Supplementary Information).

In our LSM, we only used the maximal solubility of the site as fitted parameter. This differs from the classical approach for which three parameters (the maximal solubility of the site, the site flexibility and the host site radius) are normally adjusted. We found that the solubility data of Shcheka and Keppler (2012) can be well reproduced with the present LSM (Figure 7). This suggests that the present approach is appropriate and can be used for predicting NG solubilities in a host lattice site at the extreme $P / T$ conditions of the lower mantle and beyond. 

evolutions through the LM (Figure 7). For Fpc, the solubilities increase with depth for all NGs can be explained by the difference in the mechanical properties of Fpc and $\mathrm{Bg}$. Fpc is indeed softer than $\mathrm{Bg}$ and the radius of the oxygen site in Fpc exhibits a higher reduction with increasing depth. Moreover, in the investigated $P / T$ conditions, the NGs exhibit a similarly high compressibility as Fpc.

\subsection{NG retention in the lower mantle during magma ocean crystallization}

Our lattice strain modelling results reveal that the LM phase assemblage Fpc and Bg retains efficiently $\mathrm{Ar}$ and $\mathrm{Kr}$ and to a lesser extend $\mathrm{Ne}$ and $\mathrm{Xe}$. The present solubility data are representative for NG saturated conditions and can therefore be only applied to crystallization conditions in presence of a volatile saturated liquid or melt phase. Presently, two models describing the crystallization of the magma ocean (MO) in the deep primitive Earth have been reported: (1) the classical solidification model from the bottom to the top (Solomatov and Stevenson, 1993) and (2) the more recent model that propose the onset of solidification in the mid-mantle (Labrosse et al., 2007). For both models crystallization of LM minerals at NG saturated conditions may have occurred (Supplementary Information). Our model is independent of the type of lower mantle crystallization (either bottom-up or mid-mantle). We al., 2017).

We estimated the relative abundance ratios of NGs (only stable isotopes normalized to Ar) retained in the solid LM using the solubilities extracted from the LSM (Figure 7). We compared the calculated normalized NG abundance patterns in the solid LM to those reported by Marty (2012) for the bulk mantle that are obtained by a global mass balance approach of 
radiogenic ${ }^{40} \mathrm{Ar}$. We also compared them to those given by Moreira and Kurz (2013) which were evaluated from ${ }^{3} \mathrm{He}$ abundances in OIBs. The results are presented in Figure 8a for an initial NG MO composition similar to phase Q and an additional solar contribution of $10 \%$ for Ne and Ar as suggested by Marty (2012). Our estimated Ne/Ar ratio in the solid LM is slightly larger than the one reported by Moreira and Kurz (2013) but one order of magnitude larger than the one obtained by Marty (2012). The estimated Kr/Ar and Xe/Ar ratios of the solid LM agree well with those evaluated by Marty (2012). This suggests (especially for heavy NGs) that the solid LM could represent a deep NG reservoir that is not readily sampled by plumes.

\subsection{NG replenishment from the $\mathrm{LM}$ to the atmosphere}

In the following, we discuss the contribution of NG replenishment from the LM through partial melting and plume volcanism to the present-day atmosphere over geological times. Stable Ne isotopes reveal that the present-day atmosphere has lost most of its primordial solarlike signature. This might be due to the moon-forming impact (MFI) that occurred 40-60 Myrs after Earth formation and that induced a massive erosion of primordial volatiles from the atmosphere and from the MO generated by the impact. One plausible scenario suggests that the impactor's (potentially Q-like) NG signature may have led to an overprint of the residual NGs. The ${ }^{129} \mathrm{Xe}$ abundances estimated from the ${ }^{129} \mathrm{I} /{ }^{127} \mathrm{I}$ ratio systematically constrain the loss of ${ }^{129} \mathrm{Xe}$ on Earth to $97 \%$ (Avice and Marty, 2014; Schlichting and Mukhopadhyay, 2018; and references therein).

Xe isotopic compositions also imply that most of present-day atmospheric NGs might have been acquired during late accretion of chondritic and cometary materials. This is related to the origin of atmospheric Xe that is most likely cometary U-Xe (Avice et al, 2017; Marty et al., 2017). Such relatively small impacts may have not induced a re-melting and rehomogenization of the mantle but may have modified the atmospheric NG signature relatively to the one in the MORB and OIB sources. Overall, this suggests that replenishment of LM NGs 
has not played a major role for the composition of the present-day atmosphere (Trieloff et al., 2000).

In the following, we evaluate the maximum contribution of replenished LM NGs to the present-day atmosphere. To this aim, we considered an extreme scenario which assumes that only the solid LM has captured solar-wind like Ne after the MFI and that the solar-like signature in the present-day atmosphere is entirely due to LM replenishment (Supplementary

\section{Information).}

In this model, we considered an atmosphere of the Early Earth with chondritic NG abundances that has lost its primordial solar signature during the giant impact phase of planetary accretion. We took into account the element mass fractionation and volatile loss (no isotope fractionation) due to the impact that affect lighter NGs to a larger extend. Due to the lack of data on the effect of the impact loss for all NGs, we scaled the losses of $\mathrm{Kr}$, $\mathrm{Ar}$ and $\mathrm{Ne}$ to the one of Xe (75\%) (Schlichting and Mukhopadhyay, 2018) using the relations reported by Pepin (1997) for hydrodynamic escapes. This leads to residual fractions of: $25 \% \mathrm{Xe}, 10 \% \mathrm{Kr}$, 1.3\% Ar and $0.7 \% \mathrm{Ne}$. We obtained an atmospheric Neon-B component of $30.4 \%$ and a remaining $68.9 \%$ cometary and chondritic contributions (see Supplementary Information for details). From the analysis of refractory comet grains, Marty et al. (2008) established that the cometary contribution could be Q-like. This was also assumed in our model. For Xe, an additional loss of $22 \%$ was considered to account for the progressive isotope fractionation due to the ionization of dominantly light Xe isotopes by enhanced EUV flux from the young sun (Avice et al., 2017).

The resulting modelled normalized NG abundances in the atmosphere are shown in Figure 8b. The obtained $\mathrm{Kr} / \mathrm{Ar}$ and $\mathrm{Xe} / \mathrm{Ar}$ ratios are close to those of the present-day atmosphere. The modelled Ne/Ar ratio is however much lower than the present-day one. In order to increase the Ne/Ar ratio, it is necessary to include solar contributions because the 
$522 \mathrm{Ne} / \mathrm{Ar}$ ratios of the LM, comets and chondrites are below the atmospheric ratio. A solar-like $523 \mathrm{Ne} /$ Ar ratio could originate from the outgassing of the Earth's core or could have been captured 524 in the early atmosphere due to solar-wind irradiation. The required addition of a high solar-like $525 \mathrm{Ne} / \mathrm{Ar}$ ratio from another reservoir implies a significantly lower contribution of LM NGs to the 526 present-day atmosphere. This conclusion is consistent with the study of Holland et al. (2009) in which they found that $\mathrm{Kr}$ and Xe play only a minor role in determining the NG composition of the modern atmosphere. All these arguments thus suggest that the LM may not be fully outgassed and could be an available NG reservoir through geologic times.

\section{Acknowledgements}

We thank the reviewers for their constructive comments that helped improve the manuscript. We also greatly appreciated the way the editor handled it. We thank the ESRF for up the experiments, F. Perrin, S. Pasternak, J.-L Devidal and J. Jacobs for technical assistance. MAB acknowledges the support of the Labex ClerVolc (This is laboratory of Excellence ClerVolc contribution number $\mathrm{xxxx}$ ).

\section{References}

Allègre, C.J., Staudacher, T., Sarda, P., Kurz, M., 1983. Constraints on evolution of Earth's mantle from rare gas systematics. Nature 303, 762-766,

DOI: https://doi.org/10.1038/303762a0.

Allègre, C.J., Turcotte, D., 1986. Implications for a two-component marble-cake mantle. Nature, 323, 123-127, DOI: https://doi.org/10.1038/323123a0.

Auzende, A.-L., Badro, J., Ryerson, F.J., Weber, P.K., Fallon. S.J., Addad, A., Siebert, J., 
ferropericlase: New insights into bulk lower-mantle geochemistry. Earth Planet. Sci. Lett., 269, 164-174. DOI: https://doi.org/10.1016/j.eps1.2008.02.001.

547

Avice, G., Marty, B., 2014. The iodine-plutonium-xenon age of the Moon-Earth system revisited. Philos. Trans. R. Soc. Lond. Ser. A, Math. Phys. Sci. 372, 20130260. DOI: https://doi.org/10.1098/rsta.2013.0260.

Avice, G., Marty, B., Burgess, R., 2017. The origin and degassing history of the Earth's atmosphere revealed by Archean xenon. Nature Com., 8:15455, 1-9. DOI: https://doi.org/10.1038/ncomms15455.

Baron, M., Lord, O., Myhill, R., Thomson, A. R., Wang, W. Tronnes, R.G., Walter, M.J., 2017. Experimental constraints on melting temperatures in the $\mathrm{MgO}-\mathrm{SiO}_{2}$ system at lower mantle pressures. Earth Planet. Sci. Lett., 472, 186-196,

DOI: https://doi.org/10.1016/j.eps1.2017.05.020.

Blundy, J., Wood, B., 2003. Partitioning of trace elements between crystals and melts. Earth

Bouhifd, M.A., Jephcoat, A.P., 2006. Aluminium control of argon solubility in silicate melts under pressure. Nature, 439, 961-964, DOI: https://doi.org/10.1038/nature04583.

Brooker, R.A., Du, Z., Blundy, D.J., Kelley, S.P., Allan, N.L., Wood, B.J., Chamorro, E.M., Bouhifd, M.A., Jephcoat, A.P., Heber, V.S., Kelley, S.P., 2013. Helium in the Early Earth core. Nat. Geosci., 6, 982-986, DOI: https://doi.org/10.1038/ngeo1959.

Wartho, J.A., Purton, J.A., 2003. The 'zero charge' partitioning behaviour of noble gases during mantle melting. Nature, 423, 738-741, DOI: https://doi.org/10.1038/nature01708.

Campbell, A.J., 2008. Measurement of temperature distributions across laser heated samples by multispectral imaging radiometry. Rev. Sci. Instrum., 79, 015108, DOI: https://doi.org/10.1063/1.2827513. 
569 Carroll, M.R., Stolper, E.M., 1993. Noble gas solubilities in silicate melts and glasses: New 570 experimental results for argon and the relationship between solubility and ionic porosity.

571 Geochim. Cosmochim. Ac., 57, 5039-5051, DOI: https://doi.org/10.1016/00167037(93)90606-W.

573 Chamorro-Perez, E., Gillet, P., Jambon, A., 1996. Argon solubility in silicate melts at very high pressures. Experimental set-up and preliminary results for silica and anorthite melts. Earth Planet. Sci. Lett., 145, 97-107, DOI: https://doi.org/10.1016/S0012-821X(96)00188-4.

Du, Z., Lee, K.M., 2014. High-pressure melting of $\mathrm{MgO}$ from (Mg,Fe)O solid solutions. Geophys. Res. Lett., 41, 8061 - 8066, DOI: https://doi.org/10.1002/2014GL061954.

Fischer, R. A., Langenhorst, F., Nakajima, Y., Campbell, A.J., Forst, D.J. Falko, D. H., Miyajima, N. Pollok, K., Rubie, D., 2015. High pressure metal-silicate partitioning of Ni,

O. Geochim. Cosmochi. Ac., 167, 177-194. DOI: https://doi.org/10.1016/j.gca.2015.06.026.

Heber, V.S., Brooker, R.A., Kelley, S.P., Wood, B.J., 2007. Crystal-melt partitioning of noble gases (helium, neon, argon, krypton, and xenon) for olivine and clinopyroxene. Geochimica Cosmochimica Acta, 71, 1041-1061, DOI: https://doi.org/10.1016/j.gca.2006.11.010.

Hofman, A.W., Hart, S.R., 1978. An assessment of local and regional isotopic equilibration in the mantle. Earth Planet. Sci. Lett., 38, 44-62, DOI: https://doi.org/10.1016/0012$821 X(78) 90125-5$.

Holland G., Cassidy M., Ballentine C.J., 2009. Meteorite Kr in Earth's mantle suggests a late accretionary source for the atmosphere. Science 326, 1522-1525, DOI: https://doi.org/10.1126/science.1179518.

Jackson, C.R.M., Parman, S.W., Kelley, S.P., Cooper, R.F., 2013. Noble gas transport into the mantle facilitated by high solubility in amphibole. Nat. Geosci.. 6, 562-565, DOI: https://doi.org/10.1038/ngeo1851. 
594

595

596

597

598

599

600

601

602

603

604

605

606

607

608

609

610

611

612

613

614

615

616

Jephcoat, A.P., 1998. Rare-gas solids in the Earth's deep interior. Nature 393, 355-358, DOI: https://doi.org/10.1038/30712.

Kantor, I, Dubrovinsky, L., McCammon, C., Steinle-Neumann, G., Kantor, A., 2009. Shortrange order and $\mathrm{Fe}$ clustering in $\mathrm{Mg}_{1-x} \mathrm{Fe}_{x} \mathrm{O}$ under high pressure. Physical Rev. B, 80, 014204, DOI: https://doi.org/10.1103/PhysRevB.80.014204.

Karato, S-I., 2016. Physical basis of trace element partitioning: A review. Am. Mineral., 101, 2577-2593, DOI: https://doi.org/10.2138/am-2016-5665.

Labrosse, J.W., Hernlund, N., Coltice, A., 2007. A crystallizing dense magma ocean at the base of the Earth's mantle. Nature, 450, 866-869, DOI: https://doi.org/10.1038/nature06355.

Lord, O.T., Wood, I. G., Dobson, D. P., Vočadlo, L., Wang, W. Thomson, A. R., Wann, E.T.H., Morard, G., Mezouar, M., Walter, M.J., 2014. The melting curve of Ni to 1 Mbar. Earth Planet. Sci. Lett., 408, 2014, 226-236, DOI: https://doi.org/10.1016/j.eps1.2014.09.046.

Martin, P.M., Vathonne, E., Carlot, G., Delorme, R., Sabathier, C., Freyss, M., Garcia, P., Bertolus, M., Glatzel, P., Proux, O., 2015. Behavior of fission gases in nuclear fuel: XAS characterization of $\mathrm{Kr}$ in $\mathrm{UO}_{2}$. J. Nucl. Mater., 466, 379-392, DOI: https://doi.org/10.1016/j.jnucmat.2015.08.019.

Marty, B., Altwegg, K., Balsiger, H., Bar-Nun, A., Bekaert, D.V., Berthelier, J.-J., Bieler, A., Briois, C., Calmonte, U., Combi, M., De Keyser, J., Fiethe, B., Fuselier, S.A., Gasc, S., Gombosi, T.I., Hansen, K.C., Hässig, M., Jäckel, A., Kopp, E., Korth, A., Le Roy, L., Mall, U., Mousis, O., Owen, T., Rème, H., Rubin, M., Sémon, T., Tzou, C.-Y., Waite, J.H., Wurz., P., 2017. Xenon isotopes in 67P/Churyumov-Gerasimenko show that comets contributed to Earth's atmosphere. Science, 356, 6342, 1069-1072, DOI: https://doi.org/10.1126/science.aal3496. 
Marty, B., 2012. The origins and concentrations of water, carbon, nitrogen and noble gases on Earth. Earth Planet. Sci. Lett., 313-314, 56-66, DOI: https://doi.org/10.1016/j.epsl.2011.10.040.

Marty, B., Palma, R.L., Pepin, R.O., Zimmermann, L., Schlutter, D.J., Burnard, P., Westphal, A.J., 2008. Helium and Neon abundances and compositions in cometary matter. Science, 319, 75-78, DOI: https://doi.org/10.1126/science.1148001.

Matsuda, J., Sudo, M., Ozima, M., Ito, K., Ohtaka, O., Ito, E., 1993. Noble gas partitioning between metal and silicate under pressure. Science, 259, 788-90, DOI: https://doi.org/10.1126/science.259.5096.788

Morard, G., Andrault, D., Guignot, N., Sanloup, C., Mezouar, M., Petitgirard, S., Fiquet G., 2008. In situ determination of $\mathrm{Fe}-\mathrm{Fe}_{3} \mathrm{~S}$ phase diagram and liquid structural properties up to 65 GPa. Earth Planet. Sci. Lett., 272, 620-626, DOI: ttps://doi.org/10.1016/j.epsl.2008.05.028.

Morard, G., Andrault, D., Guignot, N., Siebert, J., Garbarino, G., Antonangeli, D, 2011. Melting of $\mathrm{Fe}-\mathrm{Ni}-\mathrm{Si}$ and $\mathrm{Fe}-\mathrm{Ni}-\mathrm{S}$ alloys at megabar pressures: implications for the coremantle boundary temperature. Phys. Chem. Min., 38, 767-776. DOI: https://doi.org/10.1007/s00269-011-0449-9.

Moreira, M., 2013. Noble gas constrains on the origin and evolution of the Earth's volatiles. Geochem. Perspect., 2, 229-403.

Moreira, M., Kurz, M.D. 2013. Noble gases as tracers of mantle processes and magmatic degassing. Chapter 12. In: Advances in Isotope Geochemistry (Ed: P. Burnard). Recherche Scientifique, Centre de Recherches Pétrographiques et Centre National de laVandoeuvrelès-Nancy France. DOI : DOI https://doi.org/10.1007/978-3-642-28836-4_12 
Mori, Y., Ozawa, H., Hirose, K., Sinmyo, R., Tateno, S., Morard, G., Ohishi, Y., 2017. Melting experiments on $\mathrm{Fe}-\mathrm{Fe}_{3} \mathrm{~S}$ system to $254 \mathrm{GPa}$. Earth Planet. Sci. Lett., 464, 135-141. DOI: https://doi.org/10.1016/j.epsl.2017.02.021.

Mukhopadhyay, S., 2012. Early differentiation and volatile accretion recorded in deep mantle neon and xenon. Nature, 486, 101-104, DOI: https://doi.org/10.1038/nature11141.

Niwa, K., Miyakawa, C., Yagi, T., Matsuda, J.-i., 2013. Argon solubility in $\mathrm{SiO}_{2}$ melt under high pressures: A new experimental result using laser-heated diamond anvil cell. Earth Planet. Sci. Lett., 363, 1, 1-8, DOI: https://doi.org/10.1016/j.epsl.2012.12.014.

Noordhuis, J., De Hosson, J. Th.M., 1991. Fundamental and applied aspects of noble gas bubbles in steel. Edited by S.E. Donnelly and J.H. Evans. Plenum Press. New York, p. 153165, DOI: https://doi.org/10.1007/978-1-4899-3680-6_13.

Norton, M.G, Carter, C.B., Fleischer, E., Mayer, J.W., 1992. Solid krypton in MgO. J. Mat. Res., 7, 12, DOI: https://doi.org/10.1557/JMR.1992.3171.

Pepin, R. O., Porcelli, D., 2006. Xenon isotope systematics, giant impacts, and mantle degassing on the early Earth. Earth Planet. Sci. Lett., 250 (3-4), 470-485, DOI: https://doi.org/10.1016/j.epsl.2006.08.014.

Pepin, R. O., Porcelli, D., 2002. Origin of noble gases in the terrestrial planets. Rev. Mineral. Geochem., 47, 191-246, DOI: https://doi.org/10.2138/rmg.2002.47.7.

Pepin, R.O., 1997. Evolution of Earth's noble gases: consequences of assuming hydrodynamic loss driven by giant impact. Icarus, 126, 148-156, DOI: https://doi.org/10.1006/icar.1996.5639.

Rosa, A.D., Garbarino, G., Briggs, R., Svitlyk, V., Morard, G., Bouhifd, M.A., Jacobs, J., Irifune, T., Mathon, O., Pascarelli, S., 2018. Effect of the fcc-hcp martensitic transition on the equation of state of solid krypton up to $140 \mathrm{GPa}$. Physical Rev. B, 97, 094115. DOI: https://doi.org/10.1103/PhysRevB.97.094115. 
Rubie D. C., Frost D. J., Mann U., Asahara Y., Nimmo F., Tsuno K., Kegler P., Holzheid A., Palme, H., 2011. Heterogeneous accretion, composition and core-mantle differentiation of the Earth. Earth Planet. Sci. Lett., 301, 31-42, DOI: https://doi.org/10.1016/j.epsl.2010.11.030.

Schlichting, H. E., Mukhopadhyay, S., 2018. Atmosphere impact losses. Space Sci. Rev., 214:34, 1-31, DOI: https://doi.org/10.1007/s11214-018-0471-z.

Shcheka, S.S., Keppler, H., 2012. The origin of the terrestrial noble-gas signature. Nature, 490, 531-534, DOI: https://doi.org/10.1038/nature11506.

Solomatov, V.S., Stevenson, D.J., 1993. Nonfractional crystallization of a terrestrial magma ocean. J. Geophys. Res. 98, 5391-5406. DOI: https://doi.org/10.1029/92JE02579.

Tan, Z. Budnick, J.I., Pease, D.M., Namavar, F., 1991. X-ray absorption of krypton precipitates in solid matrices. Phys. Rev. B, 43, 3, 1987-1992, DOI: https://doi.org/10.1103/physrevb.43.1987.

Trieloff, M., Kunz, J., Clague, D.A., Harrison, D., Allègre, C.J., 2000. The nature of pristine noble gases in mantle plumes. Science 288, 1036-1039. DOI: https://doi.org/10.1126/science.288.5468.1036

Watson, E.B., Thomas J.B., Cherniak, D.J., 2007. 40Ar retention in the terrestrial planets. Nature, 449, 299-304. DOI: https://doi.org/10.1038/nature06144

Zhang, Y., Zhu., X., 1995. Atomic radii of noble gas elements in condensed phases. Am. Min., 80, 670-675, DOI: https://doi.org/10.2138/am-1995-7-807. 


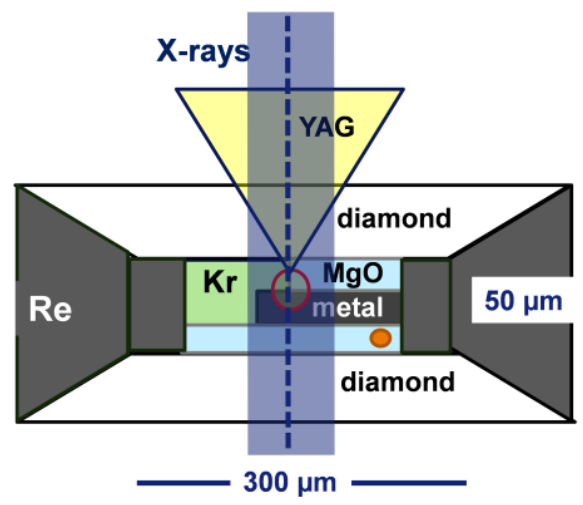

687

688 Figure 1. Schematic view of a typical diamond anvil cell sample loading (Cell_2, Table 1 and Figure S1) designed for the present experiments. A diamond culet size of $300 \mu \mathrm{m}$ allows reaching $60 \mathrm{GPa}$. A metal foil (gray) is sandwiched between two $\mathrm{MgO}$ pellets (light blue). On the laser-heated side, the metal foil is not fully covered by $\mathrm{MgO}$. The remaining sample chamber was filled with supercritical $\mathrm{Kr}$ (250 bars). For the partitioning experiments, the sample was heated on one side at the contact surface of the three materials. In the experiments carried out up to $60 \mathrm{GPa}$, the laser was slightly defocused (yellow triangle) to provide a larger laser spot size of approximately 40-60 $\mu \mathrm{m}$ in diameter. At the K-edge energy of $\operatorname{Kr}(14.3 \mathrm{keV})$ the focused X-ray beam (blue dashed line) exhibited large tails of $\sim 50 \mu \mathrm{m}$ at full width half maximum adjacent to the focused X-ray beam (blue shaded area). These tails arise from the deep penetration of the X-ray beam in the bended polychromatic $\operatorname{Si}(111)$ crystal used for horizontal focusing. This effect becomes significant for X-ray beam energies above $10 \mathrm{keV}$. 

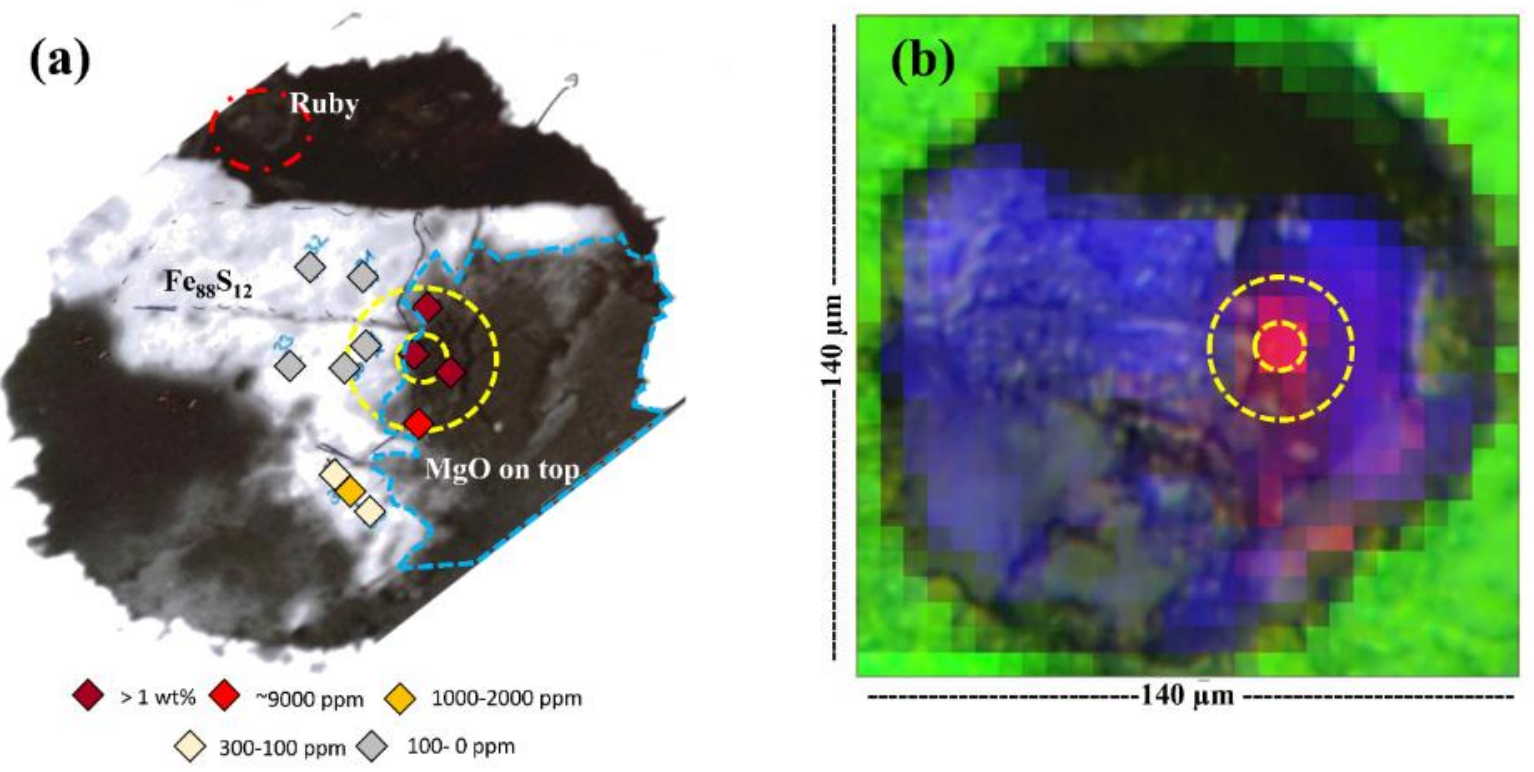

Figure 2. (a) Back scattered electron image of the sample Cell_1 (Table 1). The diamond symbols indicate the positions of EMPA measurements (Table S1), the symbol colors scale with the measured $\mathrm{Kr}$ concentrations in each point as given in the legend below the figure. The position of the ruby sphere and $\mathrm{MgO}$ pellet (Fpc in the heating spot) placed next to and on top of the Fe-S-alloy are outlined by a red circle and a blue dashed line, respectively. (b) Photograph of the same sample superimposed on the false color map of the $\mu$ XRF element distribution. The intensity of each color scales with the signal intensities of the corresponding $\mathrm{XRF}$ emission line of the element that is proportional to its concentration (green $\mathrm{Re} \mathrm{L}_{\alpha}$, blue Fe $\mathrm{K}_{\alpha}$, and pink $\mathrm{Kr} \mathrm{K}_{\alpha}$ ). Note that the $\mathrm{MgO}$ pellet cannot be observed in this figure because the $\mathrm{Mg}$ and $\mathrm{O} \mathrm{K}_{\alpha}$ emission lines are completely absorbed by the air volume located between the sample and the XRF detector. The yellow dashed circles delineate the positions of the central laser-heated hotspot (small circle with a diameter of $20 \mu \mathrm{m}$ ) and the entire laser spot (big circle with a diameter of $40 \mu \mathrm{m})$. 

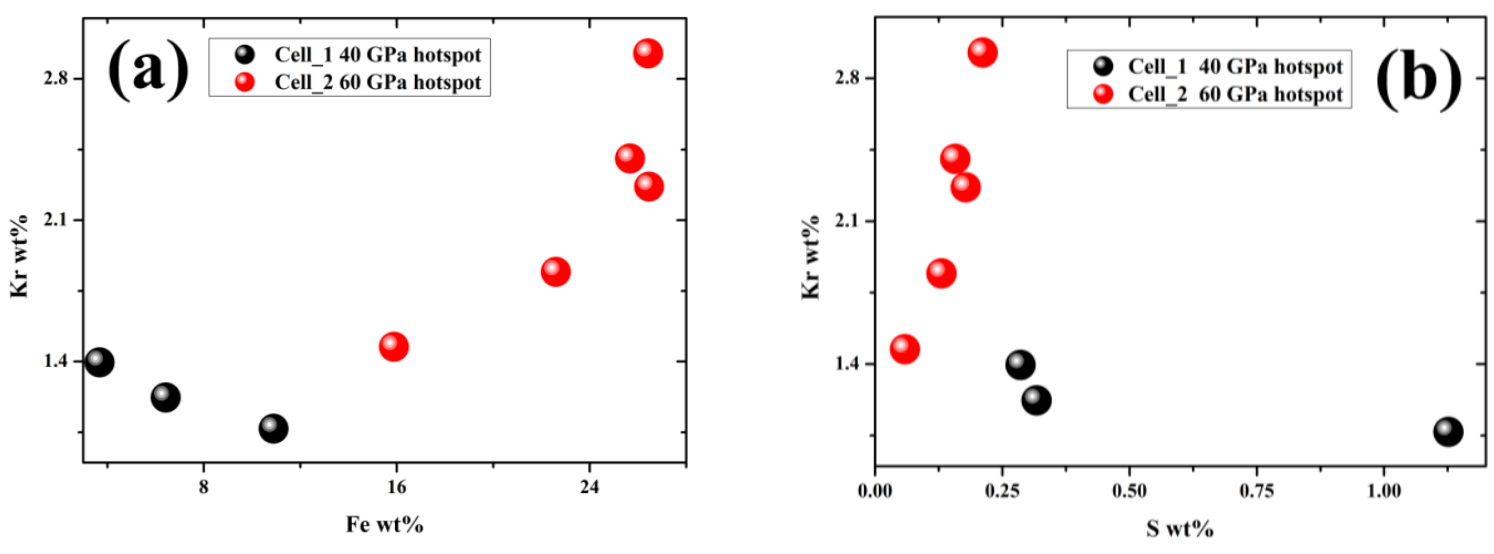

Figure 3. Measured Kr concentrations in Fpc after quenching of laser heated samples subjected to $2300 \mathrm{~K}$ and $40 \mathrm{GPa}$ (black circles) and $60 \mathrm{GPa}$ (red circles) as a function of (a) the Fe content and (b) the S content (in wt.\%). Only data acquired in the center of the laser-heated hotspot region (within a diameter of $20 \mu \mathrm{m}$ ) are shown (Table 1 and S1). Uncertainties on the EMPA measurements are within the symbol size for $\mathrm{Kr}$ and $\mathrm{Fe}$ (103 and $816 \mathrm{ppm}$, respectively). The detection limits of S (642 ppm) exceed the measured quantities for most points and therefore plot (b) can only be used for evaluating chemical trends. 

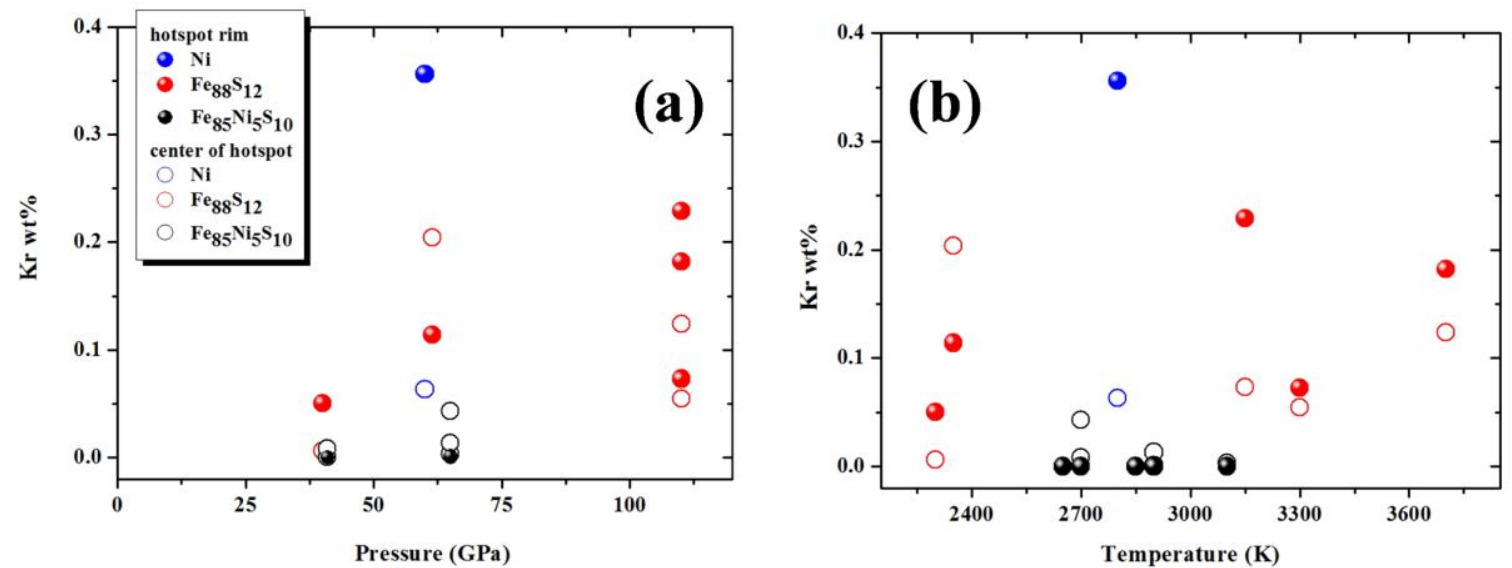

729 Figure 4. Averaged $\mathrm{Kr}$ concentrations in metallic melts with different compositions after

730 quenching as a function of (a) pressure and (b) temperature. Open and filled symbols indicate

731 the averaged data acquired in the central portion of the laser hotspot (within a diameter of 20

$732 \mu \mathrm{m}$ ) and at the rim of the hotspot (within a diameter range of 20-40 $\mu \mathrm{m}$ ), respectively. 

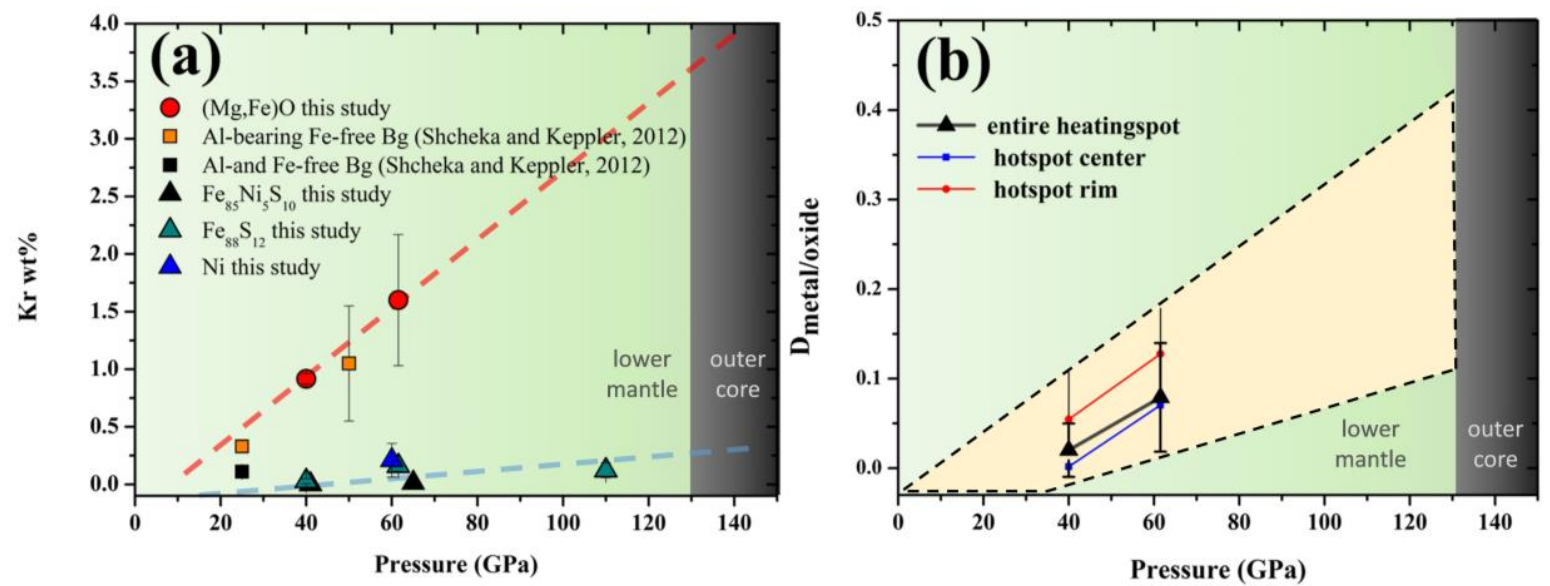

734

735

736

737

Figure 5 (a) Estimated maximal $\mathrm{Kr}$ solubilities in Fpc and metallic melts (red squares and black, blue and cyan triangles) as a function of pressure at $2300 \mathrm{~K}$. The solubilities are obtained by averaging up to 10 individual measurements (Table $\mathbf{1}$ and S1). The extrapolation of solubility data to the core mantle boundary (CMB) conditions is delineated by red and cyan dashed lines for Fpc and $\mathrm{Fe}_{88} \mathrm{~S}_{12}$, respectively. The results of the $\mathrm{Kr}$ solubility in Fe-free and Al-bearing bridgmanite (Bg) from Shcheka and Keppler (2012) are shown for comparison as black and orange squares. They have been experimentally determined at $25 \mathrm{GPa}$ and $1800 \mathrm{~K}$ and estimated from lattice strain modelling at $50 \mathrm{GPa}$. (b) Approximated partitioning coefficient $\mathrm{D}_{\text {metal/oxide }}$ between $\left(\mathrm{Mg}_{1-\mathrm{x}}, \mathrm{Fe}_{\mathrm{x}}\right) \mathrm{O}$ and $\mathrm{Fe}{ }_{88} \mathrm{~S}_{12}$ for $\mathrm{Kr}$ as a function of pressure at 2300 K (Cell_1-3, Table 1). The black triangles, blue squares and red circles indicate the calculated D values using measurements from the entire heating spot (within a diameter of $40 \mu \mathrm{m}$ ), the central portion of the hotspot (within a diameter of $20 \mu \mathrm{m}$ ) and the outer rim of the hotspot (within a diameter range of 20-40 $\mu \mathrm{m}$ ), respectively. The yellow shaded area indicates the

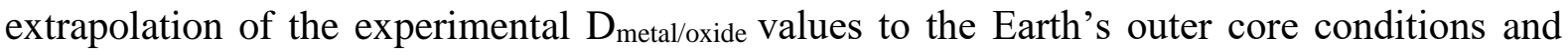
takes into account the uncertainties. 

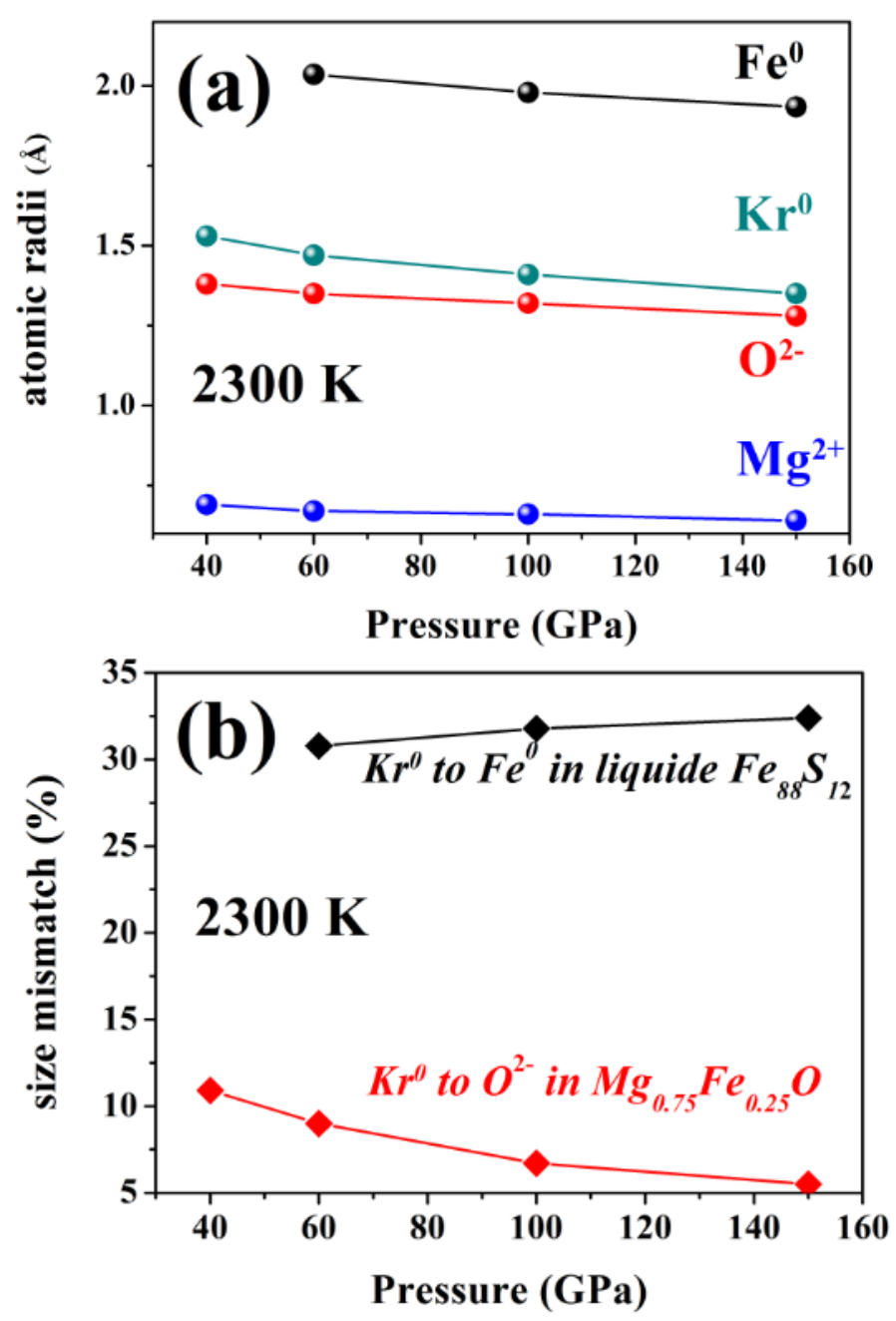

750 Figure 6 (a) Calculated atomic radii of zero-charged $\mathrm{Kr}^{0}$ in solid fcc $\mathrm{Kr}, \mathrm{Fe}^{0}$ in liquid $\mathrm{Fe}_{88} \mathrm{~S}_{22}$ 751 and $\mathrm{O}^{2-}$ and $\mathrm{Mg}^{2+}$ in solid $\mathrm{Mg}_{0.75} \mathrm{Fe} 0.25 \mathrm{O}$ as a function of pressure at $2300 \mathrm{~K}$. The radii have 752 been calculated using the thermal equation of states of the solids and density data of the liquids.

753 (b) Evolution of the size mismatch (in \%) with pressure at $2300 \mathrm{~K}$ between the radii of zerocharged $\mathrm{Kr}^{0}$ and oxygen vacancies in $\mathrm{Mg}_{0.75} \mathrm{Fe}_{0.25} \mathrm{O}\left(\mathrm{O}^{2-}\right)$ and vacant hard-sphere sites in $\mathrm{Fe}_{88} \mathrm{~S}_{22}$ $\left(\mathrm{Fe}^{0}\right)$ (See Supplementary Information for more details). 


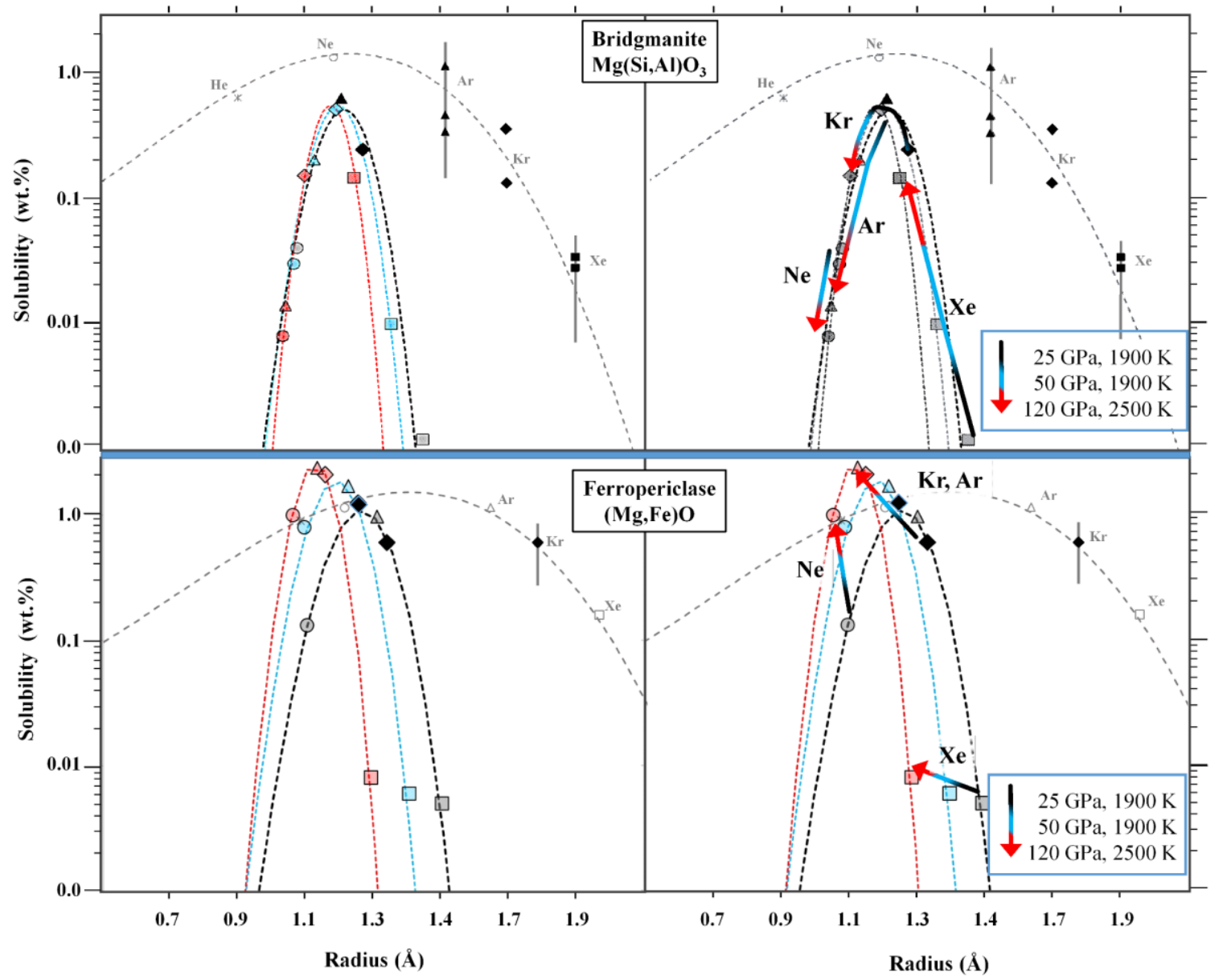

Figure 7. Left panels: Solubility trend versus NG radius in oxygen vacancies of Fe-free Albearing $\mathrm{Bg}\left(\mathrm{Mg}(\mathrm{Al}, \mathrm{Si}) \mathrm{O}_{3}\right.$, top) and $\mathrm{Fpc}((\mathrm{Mg}, \mathrm{Fe}) \mathrm{O})$, bottom) at different $P / T$ conditions obtained from lattice strain modelling (Supplementary Information), (gray: ambient; black: $25 \mathrm{GPa}$ and $1900 \mathrm{~K}$; blue: $50 \mathrm{GPa}$ and $1900 \mathrm{~K}$; red: $120 \mathrm{GPa}$ and $2500 \mathrm{~K})$. Squares: Xe; diamonds: Kr; triangles: Ar; circles: Ne; stars: He. Filled black symbols indicate the solubilities obtained experimentally in this study and by Shcheka and Keppler (2012), the uncertainties on the solubilities are represented by gray bars. The models obtained from the classical lattice strain approach (gray dashed lines) are compared to those obtained with the extended approach developed in this study (dotted colored lines). Note that in the classical approach the experimentally determined solubilities are fitted to ambient condition NG radii $\left(r_{\mathrm{i}}\right)$ by adjusting the host site flexibility $\left(E_{m}\right)$, the maximum solubility of the site $\left(c_{0}\right)$ and the host site radii $\left(r_{0}\right)$. 
In the extended approach $r_{\mathrm{i}}, r_{0}$ and $E_{m}$ are fixed to the calculated values derived from the thermoelastic data obtained at high $P / T$ conditions. In this case, the only fitting parameter is $c_{0}$.

Right panels: NG solubility trends from the top to the bottom of the LM indicated by arrows

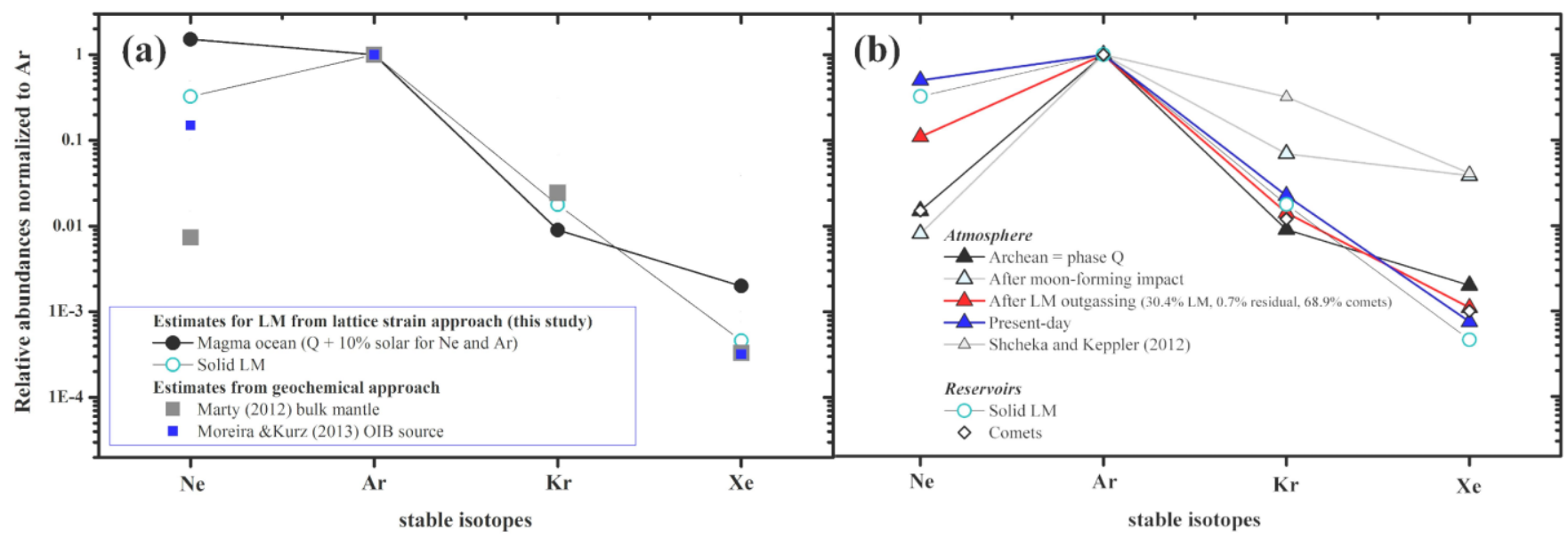

778 Figure 8. (a) Abundances of ${ }^{20} \mathrm{Ne},{ }^{36} \mathrm{Ar},{ }^{84} \mathrm{Kr}$ and ${ }^{130} \mathrm{Xe}$ (stable isotopes) normalized to ${ }^{36} \mathrm{Ar}$ dissolved in the magma ocean (MO, black circles) and retained in the solid mantle after MO crystallization (open circles) using the NG solubility data in LM minerals from Figure 7. Normalized abundances reported for the deep NG reservoir from Marty (2012) (gray squares) and Moreira and Kurz (2013) (blue squares) are shown for comparison. (b) Abundances of ${ }^{20} \mathrm{Ne},{ }^{36} \mathrm{Ar},{ }^{84} \mathrm{Kr}$ and ${ }^{130} \mathrm{Xe}$ normalized to ${ }^{36} \mathrm{Ar}$ in the Earth's atmosphere at different stages of its formation. It includes the abundances assumed for the Archean atmosphere (black triangles, phase Q-like), after elemental fractionation due to the moon forming impact (light blue triangles) and after NG re-injection from the LM Xe loss due to EUV irradiation and late- 
787 veneer contribution (red triangles), present-day atmosphere (blue triangles) and abundances 788 after LM outgassing reported from Shcheka and Keppler (2012) (gray triangles). The 789 normalized NG abundances in different reservoirs are also shown, including the solid LM (blue 790 open circles), cometary ice (black open diamonds) and phase Q in chondrites which are 791 equivalent to those assumed in the present model for the Archean atmosphere (black triangles). 
792

793

794

795

796

797

798

799

800

801

802

803

Table 1. Experimental runs conducted in this study sorted by loadings (Cell 1-7). We provide the following details: the number of laser-heated spots per loading, the insulating and starting material ( $\mathrm{KCl}, \mathrm{MgO}$, metal foil composition), the experimental conditions for each laser-heated spot including the maximal pressure P in GPa (the errors correspond to the standard deviation of pressures measured before and after laser-heating) and temperature $\mathrm{T}$ in $\mathrm{K}$ (errors are of the order of 100-200 K). Kr concentrations from EMPA measurements in wt.\% are given for the different phases (Fpc or metallic melts) and include averages of measurements acquired only in the hotspot center (center: within a diameter of $20 \mu \mathrm{m}$ ), only in the rim of the laser-heated spot (rim: with a diameter range of 20-40 $\mu \mathrm{m}$ from the center), in the entire hotspot region (everything: within a diameter of $40 \mu \mathrm{m}$ ) and the maximum $\mathrm{Kr}$ content measured in a single analysis (maximum). A detailed list of all measurements is provided in the Supplementary Information Table S1.

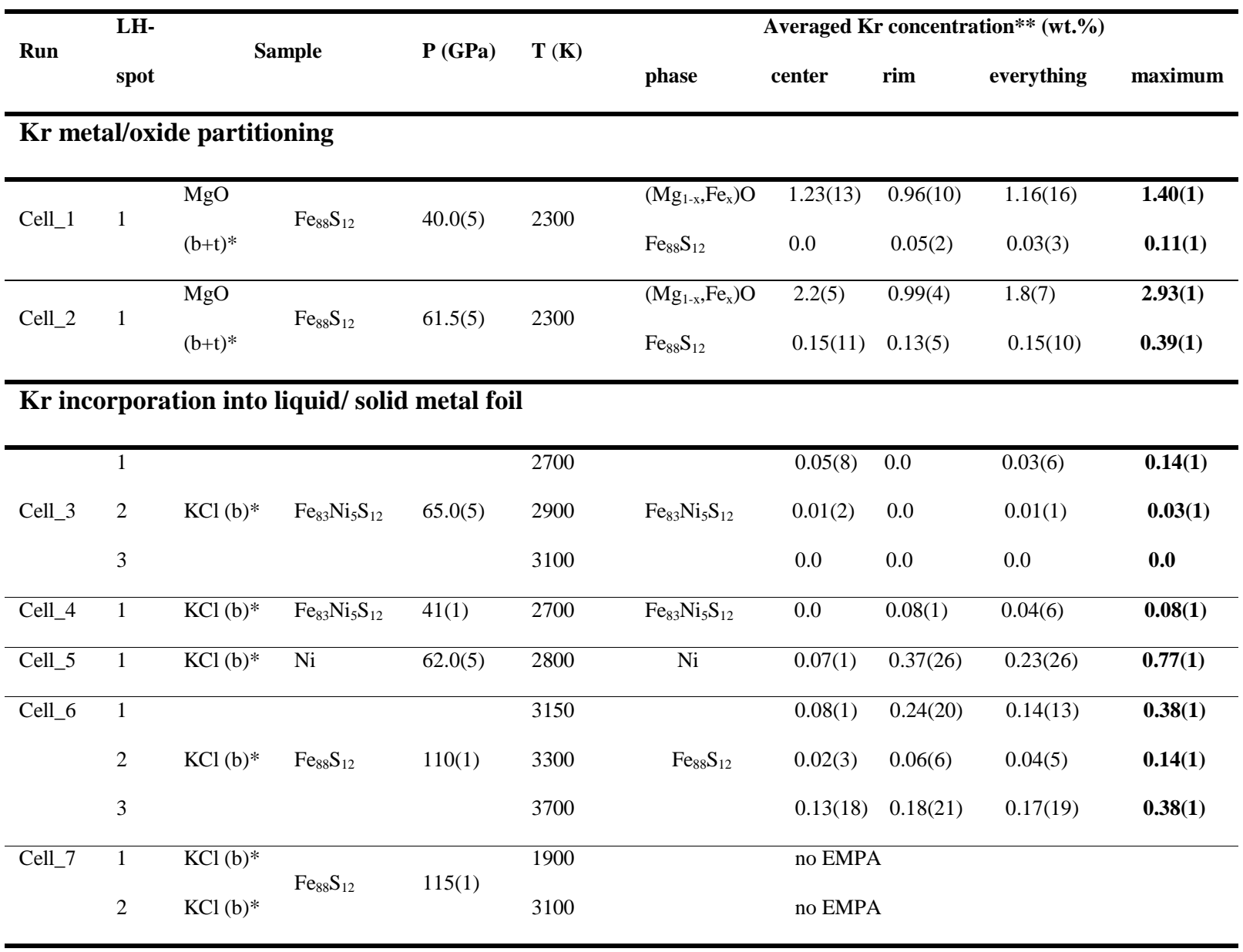

* Note: $\mathrm{b}$ and $\mathrm{t}$ denoted bottom and top, respectively.

** Reported values are averaged from 3-17 measurements, see Table S1 of the Supplementary Information. 


\section{Supplementary Information}

\section{Krypton storage capacity of the Earth's lower mantle}

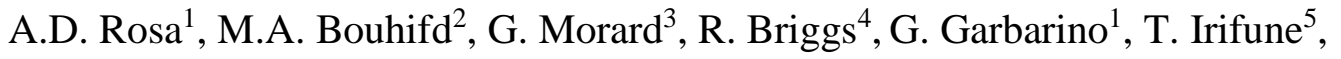
O. Mathon ${ }^{1}$, S. Pascarelli ${ }^{1}$

${ }^{6}$ European Synchrotron Radiation Facility (ESRF), 71, Avenue des Martyrs, Grenoble, France.

${ }^{7}$ Laboratoire Magmas et Volcans, Université Clermont Auvergne, CNRS, IRD, OPGC, F-63000 Clermont-Ferrand, France.

${ }^{8}$ Sorbonne Université, Muséum National d'Histoire Naturelle, UMR CNRS 7590, IRD, Institut de Minéralogie, de Physique des Matériaux et de Cosmochimie, IMPMC, 75005 Paris, France.

${ }^{9}$ Lawrence Livermore National Laboratory, Livermore, CA, United States of America

${ }^{10}$ Geodynamics Research Center, Ehime University, 2-5 Bunkyo-cho, Matsuyama 790-8577, Japan 


\section{Supplementary Information}

816 Contents

Page

817 1. Laser-heating experiments at ID24 3

818

2. XRF experiments at BM23 3

819

3. EMPA calibration and measurement results 6

820

4. Size mismatch calculations 8

821 5. $\mathrm{Kr}$ incorporation in quenched samples from X-ray absorption data 8

822

6. Lattice strain model approach and parameters 14

823 7. Formation of volatile saturated liquid/melt phase during magma ocean crystallization 16

824

8. NG replenishment model and considered isotopic Ne signatures therein 16

825

9. References 17 


\section{Supplementary Information}

826

827

828

829

830

831

832

833

834

835

836

837

838

839

840

841

842

843

844

845

846

847

\section{Laser-heating experiments at ID24}

The samples were single-sided laser-heated using the laser-heating system installed at ID24 (Pascarelli et al., 2016; Kantor et al., 2018). The temperature was determined in-situ via spectroradiometry (Giampaoli et al., 2018). The pressure was measured before and after laserheating using the ruby fluorescence signal and the ruby pressure scale after Dewaele et al. (2008) or the Raman shift of the single-crystal diamonds at the centre of the culet (Akawama and Kawamura, 2004).

\section{XRF experiments at BM23}

The X-ray energy was tuned to the $\mathrm{Kr} \mathrm{K}$-edge (14.2 keV) using a double-crystal fixed exit monochromator equipped with a pair of $\mathrm{Si}(111)$ crystals. The X-ray beam was focused down to $5 \times 5 \mu \mathrm{m}^{2}$ using a KirkPatrick-Baez mirror system (Mathon et al., 2015). The quenched samples were oriented with the laser-heated surfaces towards the incoming X-ray beam. In order to avoid shadowing of the Re gasket, the samples were rotated by $15^{\circ}$ from the incoming X-ray beam and towards the single-element silicon solid-state fluorescence detector (Vortex). The Vortex detector was positioned in backscattering geometry (rotated by $30^{\circ}$ from the incoming X-ray beam).

In a first step, finely-meshed two-dimensional $\mu \mathrm{XRF}$ elemental distribution maps at a fixed X-ray energy of $14.5 \mathrm{keV}$ were acquired for each sample with a step size of $5 \mu \mathrm{m}$. These maps enabled determining the $\mathrm{Kr}$ distribution around the laser-heating spot (Figure S1). In a second step, X-ray absorption spectra were collected in regions of high $\mathrm{Kr}$ concentrations by scanning the monochromator energy with a small mesh size of energy points $(0.4 \mathrm{eV})$ around the edge region and up to a k-range of $14 \AA^{-1}$, respectively (Figure S3 and S4). 


\section{Supplementary Information}

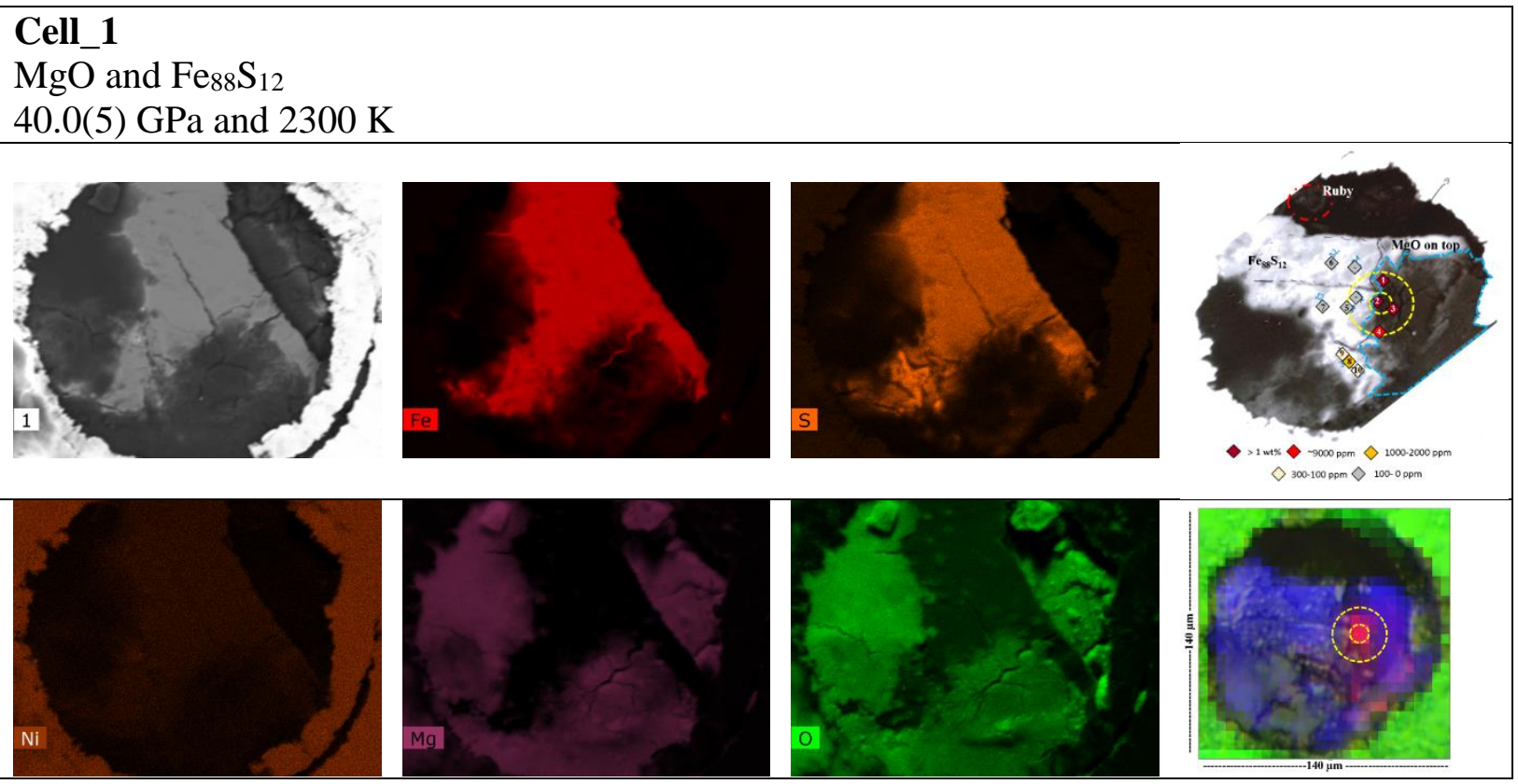

\section{Cell_2}

$\mathrm{MgO}$ and $\mathrm{Fe}_{88} \mathrm{~S}_{12}$

61.5(5) GPa and $2350 \mathrm{~K}$
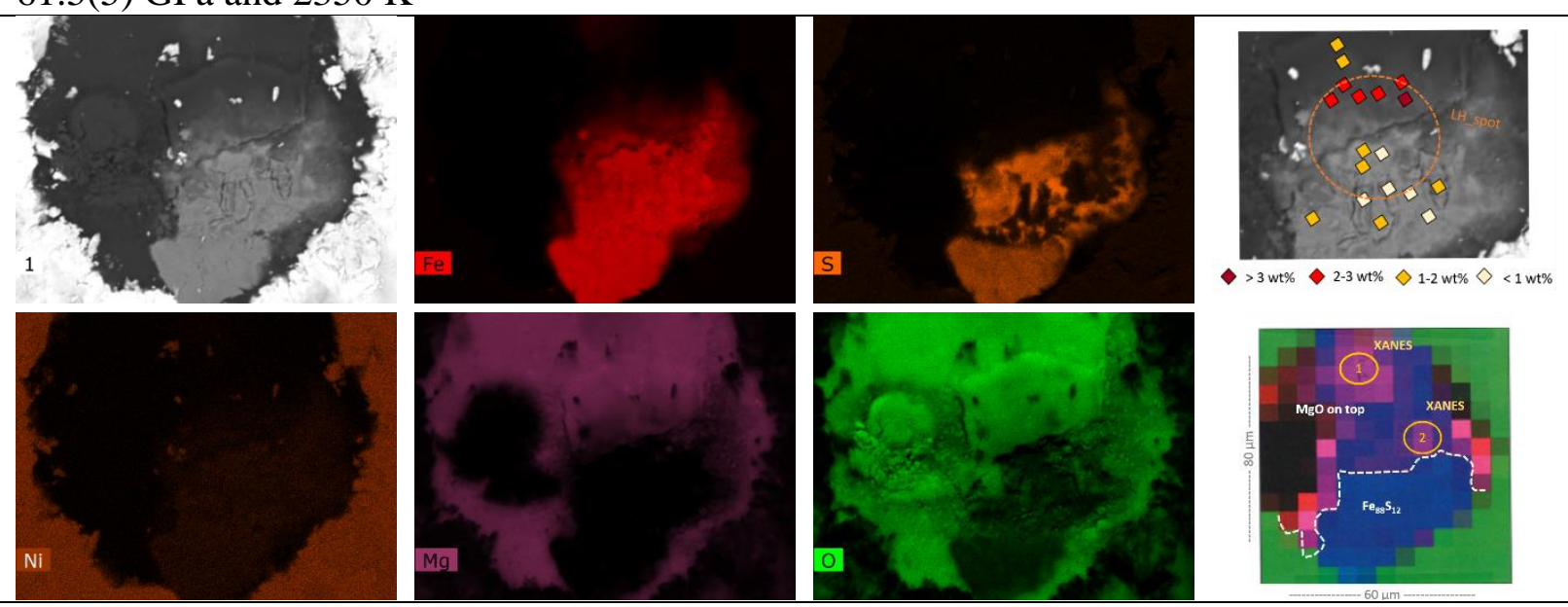

\section{Cell_3}

$\mathrm{KCl}$ and $\mathrm{Fe}_{83} \mathrm{Ni}_{5} \mathrm{~S}_{12}$

65.0(5) GPa and 2700-3100 K
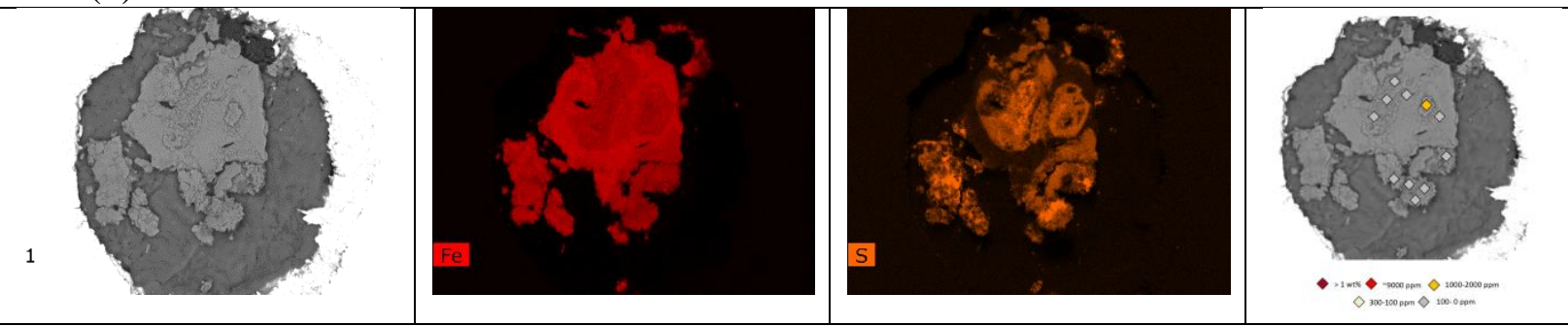


\section{Supplementary Information}
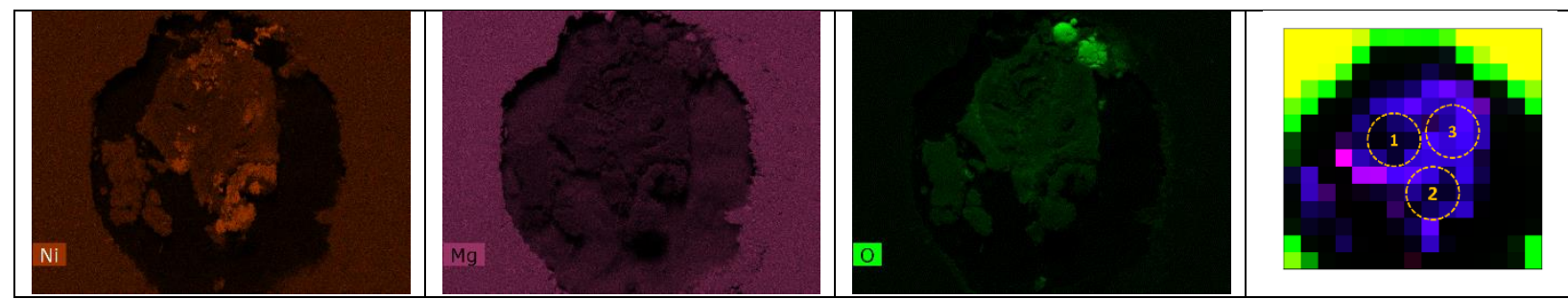

\section{Cell_6 \\ $\mathrm{KCl}$ and $\mathrm{Fe}_{88} \mathrm{~S}_{12}$}

110(1) GPa and 3150-3700 K
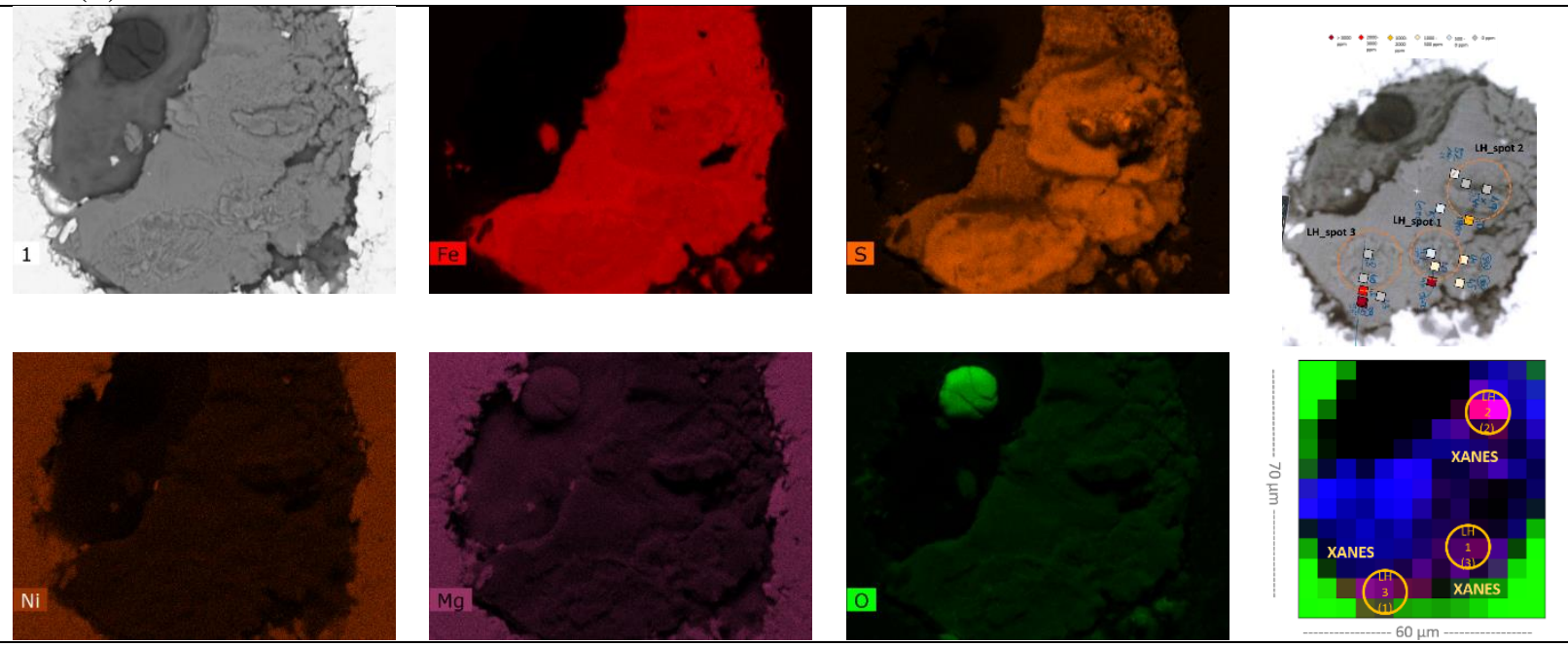

\section{Cell_7}

$\mathrm{KCl}$ and $\mathrm{Fe}_{88} \mathrm{~S}_{12}$

115(1) GPa and 1900-3100 K

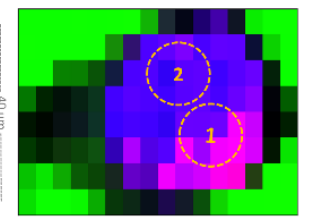

Figure S1. SEM, EMPA and $\mu X R F$ maps acquired on samples Cell_1,_2,_3, _6 and_7 (Table 1, main manuscript and Table S1). The figures for each sample include a raw back scattered electron (BSE) image and the corresponding elemental distribution maps of $\mathrm{Fe}$ (red), $\mathrm{S}$ (orange), $\mathrm{Ni}$ (brown), $\mathrm{Mg}$ (pink) and $\mathrm{O}$ (green). The positions of acquired EMPA measurements are outlined as diamond symbols in a detailed $\boldsymbol{B S E}$ image on the right. The coloured symbols indicate the measured concentration of $\mathrm{Kr}$ as outlined in the legend below the detailed BSE images. The position of the laser spot is delineated in the detailed BSE images as yellow circles having an inner circle representing the central hot-spot region. The XRF image is shown on the right below the detailed BSE image. It represents the elemental distribution of $\mathrm{Kr}$ in red; $\mathrm{Fe}$ in blue and $O$ in green. The colour intensity scales with the abundance of the element. The sample size is given on the $\mu X R F$ image. Solid orange circles indicate the positions where X-ray absorption data were acquired. 


\section{Supplementary Information}

866

867

868

869

870

871

872

873

874

875

876

877

\section{EMPA calibration and measurment results}

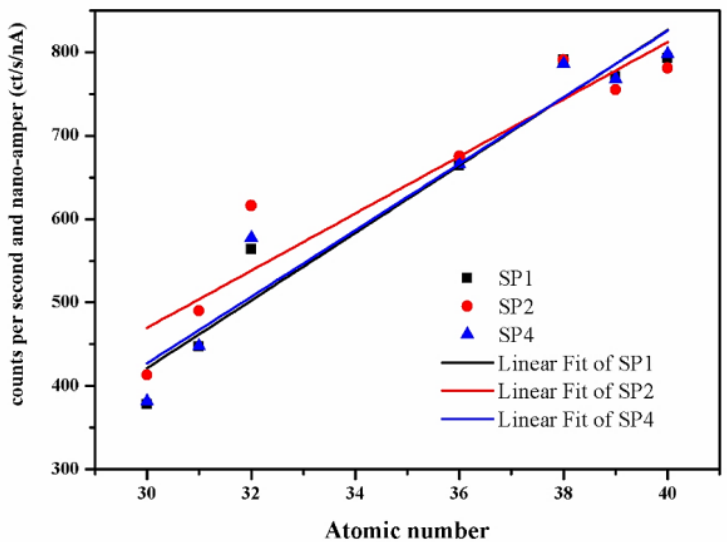

Figure S2. The EMPA Kr counts to concentration calibration using 7 standards of elements adjacent to $\mathrm{Kr}$ (from atomic number 30 to 40) for the three crystal detectors SP1, SP2 and SP3. Linear fits to the data are shown as solid lines. 


\section{Supplementary Information}

878

879

880

Table S1. EMPA concentration measurements (in wt.\%) and their distance from the centre of the laser heating spot. Averaged detection limits of elements are 530 ppm for Mg, 642 ppm for S, 816 ppm for Fe, 971 ppm for Ni and 103 ppm for Kr. Errors on temperature are in the order of 100-200 K.

\begin{tabular}{|c|c|c|c|c|c|c|c|c|}
\hline Sample, LH-spot & Mg & $\mathbf{S}$ & $\mathbf{F e}$ & $\mathbf{N i}$ & $\mathbf{K r}$ & $\mathbf{P}$ (Gpa) & $\mathbf{T}(\mathbf{K})$ & $\begin{array}{l}\text { Distance from centre } \\
\text { of hotspot }\end{array}$ \\
\hline \multirow[t]{4}{*}{ Cell_1, MgO } & 47.67 & 0.27 & 5.65 & 0 & 1.08 & $40.0(5)$ & 2300 & $\sim 10 \mu \mathrm{m}$ \\
\hline & 47.25 & 1.07 & 10.34 & 0.08 & 1.01 & & & $\sim 10 \mu \mathrm{m}$ \\
\hline & 49.84 & 0.25 & 3.26 & 0.08 & 1.24 & & & $\sim 10 \mu \mathrm{m}$ \\
\hline & 49.19 & 0.35 & 2.35 & 0.02 & 0.18 & & & $10-20 \mu \mathrm{m}$ \\
\hline \multirow[t]{6}{*}{ Cell_1, $\mathrm{Fe}_{88} \mathrm{~S}_{12}$} & 0.07 & 9.36 & 89.27 & 0.09 & 0.00 & $40.0(5)$ & 2300 & $\sim 10 \mu \mathrm{m}$ \\
\hline & 0.42 & 8.17 & 89.09 & 0.12 & 0.00 & & & $10-20 \mu \mathrm{m}$ \\
\hline & 0.14 & 8.50 & 90.11 & 0.17 & 0.00 & & & $10-20 \mu \mathrm{m}$ \\
\hline & 0.63 & 3.24 & 91.78 & 0.09 & 0.11 & & & $>20 \mu \mathrm{m}$ \\
\hline & 0.17 & 13.1 & 84.04 & 0.08 & 0.03 & & & $>20 \mu \mathrm{m}$ \\
\hline & 0.46 & 8.15 & 85.38 & 0.09 & 0.02 & & & $>20 \mu \mathrm{m}$ \\
\hline \multirow[t]{7}{*}{ Cell_2, MgO } & 40.56 & 0.06 & 15.88 & 0.00 & 1.473 & $61.5(5)$ & 2300 & $\sim 10 \mu \mathrm{m}$ \\
\hline & 35.23 & 0.21 & 26.43 & 0.02 & 2.9264 & & & $\sim 10 \mu \mathrm{m}$ \\
\hline & 41.21 & 0.13 & 22.59 & 0.01 & 1.8444 & & & $\sim 10 \mu \mathrm{m}$ \\
\hline & 38.64 & 0.16 & 25.67 & 0.01 & 2.4057 & & & $\sim 10 \mu \mathrm{m}$ \\
\hline & 38.51 & 0.18 & 26.46 & 0.03 & 2.266 & & & $\sim 10 \mu \mathrm{m}$ \\
\hline & 48.09 & 0.00 & 11.33 & 0.00 & 0.9489 & & & $10-20 \mu \mathrm{m}$ \\
\hline & 44.63 & 0.02 & 15.85 & 0.00 & 1.0297 & & & $10-20 \mu \mathrm{m}$ \\
\hline \multirow[t]{8}{*}{ Cell_2,, $\mathrm{Fe}_{88} \mathrm{~S}_{12}$} & 0.17 & 11.80 & 87.71 & 0.23 & 0.09 & $61.5(5)$ & 2300 & $<10 \mu \mathrm{m}$ \\
\hline & 0.25 & 10.37 & 88.79 & 0.20 & 0.39 & & & $<10 \mu \mathrm{m}$ \\
\hline & 0.07 & 13.38 & 86.31 & 0.17 & 0.07 & & & $\sim 10 \mu \mathrm{m}$ \\
\hline & 0.04 & 12.75 & 86.99 & 0.13 & 0.10 & & & $\sim 10 \mu \mathrm{m}$ \\
\hline & 0.02 & 2.87 & 96.94 & 0.12 & 0.05 & & & $\sim 10 \mu \mathrm{m}$ \\
\hline & 0.08 & 4.70 & 95.08 & 0.09 & 0.06 & & & $10-20 \mu \mathrm{m}$ \\
\hline & 0.09 & 4.12 & 95.56 & 0.09 & 0.14 & & & $10-20 \mu \mathrm{m}$ \\
\hline & 0.23 & 6.78 & 92.65 & 0.16 & 0.18 & & & $10-20 \mu \mathrm{m}$ \\
\hline \multirow{5}{*}{$\begin{array}{l}\mathrm{Cell}_{-1} 3, \mathrm{Fe}_{83} \mathrm{Ni}_{5} \mathrm{~S}_{12}, \\
\mathrm{LH}_{-1}\end{array}$} & 0.00 & 12.96 & 78.17 & 8.87 & 0.00 & $65.0(5)$ & 2700 & $<10 \mu \mathrm{m}$ \\
\hline & 0.00 & 7.67 & 82.49 & 9.70 & 0.14 & & & $<10 \mu \mathrm{m}$ \\
\hline & 0.01 & 13.04 & 78.97 & 7.98 & 0.00 & & & $\sim 10 \mu \mathrm{m}$ \\
\hline & 0.00 & 15.99 & 79.86 & 4.14 & 0.00 & & & $10-20 \mu \mathrm{m}$ \\
\hline & 0.00 & 11.89 & 84.73 & 3.38 & 0.00 & & & $10-20 \mu \mathrm{m}$ \\
\hline \multirow{5}{*}{$\begin{array}{l}\text { Cell_ } 3, \mathrm{Fe}_{83} \mathrm{Ni}_{5} \mathrm{~S}_{12}, \\
\mathrm{LH} \_2\end{array}$} & 0.01 & 8.95 & 80.55 & 10.49 & 0.00 & & & $<10 \mu \mathrm{m}$ \\
\hline & 0.01 & 8.92 & 76.99 & 14.05 & 0.03 & & & $\sim 10 \mu \mathrm{m}$ \\
\hline & 0.04 & 5.25 & 80.55 & 14.15 & 0.01 & & & $\sim 10 \mu \mathrm{m}$ \\
\hline & 0.01 & 7.37 & 75.06 & 17.56 & 0.00 & & & $\sim 10 \mu \mathrm{m}$ \\
\hline & $\underline{0.00}$ & 10.71 & 78.91 & 10.37 & 0.00 & & & $10-20 \mu \mathrm{m}$ \\
\hline \multirow{4}{*}{$\begin{array}{l}\text { Cell_3, } \mathrm{Fe}_{83} \mathrm{Ni}_{5} \mathrm{~S}_{12}, \\
\mathrm{LH} \_3\end{array}$} & 0.00 & 17.76 & 74.97 & 7.26 & 0.00 & & & $<10 \mu \mathrm{m}$ \\
\hline & 0.00 & 14.14 & 82.41 & 3.45 & 0.00 & $65.0(5)$ & 3100 & $\sim 10 \mu \mathrm{m}$ \\
\hline & 0.02 & 15.17 & 81.53 & 3.26 & 0.01 & & & $\sim 10 \mu \mathrm{m}$ \\
\hline & 0.00 & 15.41 & 81.22 & 3.36 & 0.00 & & & $\sim 10 \mu \mathrm{m}$ \\
\hline \multirow[t]{12}{*}{ Cell_5,Ni, LH_1 } & 0.02 & 0.02 & 0.02 & 99.91 & 0.03 & $62.0(5)$ & 2800 & $<10 \mu \mathrm{m}$ \\
\hline & 0.00 & 0.03 & 0.03 & 99.92 & 0.02 & & & $<10 \mu \mathrm{m}$ \\
\hline & 0.01 & 0.00 & 0.01 & 99.97 & 0.01 & & & $<10 \mu \mathrm{m}$ \\
\hline & 0.01 & 0.00 & 0.02 & 99.93 & 0.04 & & & $<10 \mu \mathrm{m}$ \\
\hline & 0.03 & 0.00 & 0.00 & 99.95 & 0.03 & & & $<10 \mu \mathrm{m}$ \\
\hline & 0.00 & 0.00 & 0.02 & 99.77 & 0.21 & & & $10-20 \mu \mathrm{m}$ \\
\hline & 0.00 & 0.00 & 0.01 & 99.29 & 0.70 & & & $10-20 \mu \mathrm{m}$ \\
\hline & 0.00 & 0.02 & 0.01 & 99.62 & 0.35 & & & $10-20 \mu \mathrm{m}$ \\
\hline & 0.01 & 0.00 & 0.03 & 99.19 & 0.77 & & & $10-20 \mu \mathrm{m}$ \\
\hline & 0.01 & 0.01 & 0.00 & 99.81 & 0.17 & & & $10-20 \mu \mathrm{m}$ \\
\hline & 0.00 & 0.00 & 0.00 & 99.85 & 0.15 & & & $10-20 \mu \mathrm{m}$ \\
\hline & 0.01 & 0.01 & 0.03 & 99.68 & 0.26 & & & $10-20 \mu \mathrm{m}$ \\
\hline \multirow[t]{5}{*}{ Cell_6, $\mathrm{Fe}_{88} \mathrm{~S}_{12}, \mathrm{LH}$} & 10.00 & 9.43 & 90.41 & 0.08 & 0.08 & $110(1)$ & 3150 & $<10 \mu \mathrm{m}$ \\
\hline & 0.00 & 7.60 & 92.18 & 0.14 & 0.07 & & & $<10 \mu \mathrm{m}$ \\
\hline & 0.00 & 10.29 & 89.53 & 0.11 & 0.07 & & & $\sim 10 \mu \mathrm{m}$ \\
\hline & 0.00 & 9.27 & 90.54 & 0.09 & 0.09 & & & $10-20 \mu \mathrm{m}$ \\
\hline & 0.00 & 5.98 & 93.58 & 0.06 & 0.38 & & & $10-20 \mu \mathrm{m}$ \\
\hline \multirow{6}{*}{ Cell_6, $\mathrm{Fe}_{88} \mathrm{~S}_{12}, \mathrm{LH} \_$} & 20.00 & 11.21 & 88.54 & 0.25 & 0.00 & $110(1)$ & 3300 & $<10 \mu \mathrm{m}$ \\
\hline & 0.01 & 9.13 & 90.60 & 0.25 & 0.01 & & & $<10 \mu \mathrm{m}$ \\
\hline & 0.03 & 8.37 & 91.41 & 0.13 & 0.06 & & & $<10 \mu \mathrm{m}$ \\
\hline & 0.02 & 11.45 & 88.27 & 0.12 & 0.14 & & & $\sim 10 \mu \mathrm{m}$ \\
\hline & 0.03 & 9.72 & 90.08 & 0.16 & 0.01 & & & $10-20 \mu \mathrm{m}$ \\
\hline & 0.00 & 8.53 & 91.36 & 0.09 & 0.02 & & & $10-20 \mu \mathrm{m}$ \\
\hline Cell_6, $\mathrm{Fe}_{88} \mathrm{~S}_{12}, \mathrm{LH} \_3$ & $\overline{0.00}$ & 15.08 & 84.80 & 0.12 & 0.00 & $110(1)$ & 3700 & $<10 \mu \mathrm{m}$ \\
\hline & 0.00 & 15.25 & 84.41 & 0.08 & 0.25 & & & $\sim 10 \mu \mathrm{m}$ \\
\hline & 0.00 & 7.98 & 91.54 & 0.11 & 0.38 & & & $10-20 \mu \mathrm{m}$ \\
\hline & 0.02 & 13.44 & 86.37 & 0.18 & 0.00 & & & $10-20 \mu \mathrm{m}$ \\
\hline & 0.02 & 10.05 & 89.40 & 0.17 & 0.36 & & & $10-20 \mu \mathrm{m}$ \\
\hline & 0.01 & 14.49 & 85.40 & 0.10 & 0.00 & & & $10-20 \mu \mathrm{m}$ \\
\hline
\end{tabular}




\section{Supplementary Information}

883

884

885

886

887

888

889

890

891

892

893

894

895

896

897

898

899

900

901

902

903

904

905

906

907

908

909

910

911

912

913

914

915

916

917

918

919

\section{Size mismatch calculations}

Zero-charged $\mathrm{Kr}^{0}$ atomic radii were calculated using the equation of state of fcc $\mathrm{Kr}$ determined by Rosa et al. (2018) and the assumed thermal parameters reported by Jephcoat (1998). For Fpc we calculated the anion and cation vacancy site radii using the thermal equation of state reported for $\mathrm{Mg}_{0.75} \mathrm{Fe}_{0.25} \mathrm{O}$ by Mao et al. (2011) and an assumed bond ratio between $\mathrm{Mg}^{2+}$ and $\mathrm{O}^{2-}$ of $1 / 3$ to $2 / 3$, respectively. Such bond ratios are expected from the ion-radii values at ambient conditions (Zhang and Zhu, 1995). Average atomic radii for $\mathrm{Fe}^{0}$ in the liquid were calculated using the density of liquid $\mathrm{Fe}_{88} \mathrm{~S}_{12}$ reported from shock wave experiments at Earth's core conditions (Huang et al., 2013). For calculating the hard sphere diameter from the obtained densities, we used the Percus-Yevick equation assuming the arrangement of atoms in transition metal liquids can be described by the hard sphere model (Ashcroft and Lekner, 1966) with a packing fraction of 0.44 as determined experimentally by Shen et al. (2004) for pure liquid iron. We further assumed a liquid structure consisting of zero-charged $\mathrm{Fe}^{0}$ atoms with $\mathrm{S}$ atoms sitting in the interstitial sites as proposed by Posner et al. (2017).

\section{5. $\mathrm{Kr}$ incorporation in quenched samples}

Information on the local bonding environment of $\mathrm{Kr}$ retained in the samples can be obtained from X-ray absorption spectroscopy (XAS). XAS is a local and element selective probe, sensitive to the sort and arrangement of neighbouring atoms. Several energy regions in a XAS spectrum are distinguished: The white line energy corresponds to the ionization energy of the core electron and is defined as the energy position of the first peak in the spectrums' derivative function. The X-ray absorption near edge structure (XANES) region is defined in the energy domain between 50 and $100 \mathrm{eV}$ from the white line energy. XANES provides information on the local site symmetry of the absorbing atom, bond distance distribution and sort of neighbouring atoms on the medium range scale. The extended X-ray absorption fine structure (EXAFS) corresponds to the energy region that extends $\sim 1000 \mathrm{eV}$ from the absorption edge. EXAFS is highly sensitive to the distribution and sort of nearest-neighboring atoms.

XANES and EXAFS spectra of $\mathrm{Kr}$ retained in quenched Fpc and $\mathrm{Fe}_{88} \mathrm{~S}_{12}$ (blue spectra, Cell_1 and Cell_7 Table 1) are presented in Figure S3 and S4. Comparison of these two spectra reveals a well-structured first XANES peak region in both spectra, as well as an energy shift of the white line. Despite the absence of a simple theoretical interpretation of the XANES spectra, important information is commonly extracted through the comparison to reference spectra measured on known materials as well as from full multiple scattering calculations.

In a first step, we compared the XANES spectra acquired in quenched samples to reference spectra of pure $\mathrm{Kr}$ in the gaseous, liquid and solid state collected at different pressures (black spectra, Figure S4). We observed a clear similarity between the spectra of $\mathrm{Kr}$ retained in quenched samples with those of liquid and solid krypton. This suggests that $\mathrm{Kr}$ could partly be coordinated to another $\mathrm{Kr}$ in a similar symmetrical arrangement as pure liquid or solid fcc $\mathrm{Kr}$ under pressure. 


\section{Supplementary Information}

To better interpret the experimental XANES data and constrain the structural incorporation mechanism of $\mathrm{Kr}$, we conducted full multiple scattering calculations (FMS) using the Feff9 code (Rehr et al., 2010). FMS XANES spectra were computed at the Kr K-edge for a single Kr atom replacing the anion or cation in $\mathrm{MgO}$ and $\mathrm{FeO}$. Calculations were performed on a sphere having a FMS radius of $6 \AA$. For the self-consistent loop, a cluster of $3.1 \AA$ and a convergence after 30 iterations were chosen. The core hole was calculated after the final state rule and the scattering amplitude was fixed to unity for all calculations. The XANES spectra were calculated with a fine grid of $0.05 \mathrm{eV}$. The exchange-correlation potential for the fine structure and the atomic background were computed using the Hedin-Lundquist formalism and the ground state.

The resulting calculated XANES spectra for $\mathrm{Kr}$ incorporated in $\mathrm{MgO}$ in $\mathrm{FeO}$ and in $(\mathrm{Mg}, \mathrm{Fe}) \mathrm{O}$ are shown in Figure S5. It is worth noting that only those spectra calculated for $\mathrm{Kr}$ replacing the oxygen site in $\mathrm{FeO}$ show similarities to the experimental spectra. They indeed exhibit a comparable white line slope and first XANES peak shape (Figure S5). These similarities in the XANES data imply that $\mathrm{Kr}$ atoms in the quenched samples may be entrapped in oxygen vacancies of Fpc having $\mathrm{Mg}$ and $\mathrm{Fe}$ as next-nearest neighbor. Such $\mathrm{Kr}$ substitution for neutral Schottky oxygen vacancies has been previously suggested by Martin et al. (2015) from X-ray absorption data on ion-implanted $\mathrm{UO}_{2}$. In contrast, the calculated spectra of $\mathrm{Kr}$ replacing $\mathrm{Mg}$ and $\mathrm{Fe}$ do not match with the measured $\mathrm{Kr}$ K-edge XANES data. This discards this type of substitution mechanism in the quenched samples.

To estimate the Kr next nearest neighbor bond distances in the quenched samples, we used the energy shift of the first XANES peak in the acquired spectra following the approach of DiCicco et al. (1996). Calculated pressures are in the range of 0.5-5 GPa (Figure S6). This matches the experimental XANES measurements and suggests that the $\mathrm{Kr}$ impurity atoms are enclosed under a positive confinement pressure or stress. Similar pressures have been reported for $\mathrm{Kr}$ ionimplanted metal foils $\mathrm{MgO}$ and $\mathrm{UO}_{2}$ (Tan et al., 1991; Norton et al., 1992; Martin et al., 2015;).

Based on these observations, we propose that Kr impurity clusters may have formed during $P / T$ quenching. The significant expansion of $\mathrm{Kr}$ (more than 50\% during $\mathrm{P}$ quenching from 40-60 $\mathrm{GPa}$ (Rosa et al., 2018) may favor short range diffusion of initially homogenously distributed $\mathrm{Kr}$ atoms and their precipitation into NG nano-impurity clusters. This short range diffusion and lattice rearrangement may be driven by the lattice strains that $\mathrm{Kr}$ atoms exert on the host lattice at room conditions. It has been previously shown that structures hosting large impurity atoms tend to form impurity clusters by a point defect coalescence mechanism. This mechanism allows reducing the tensile stresses by transforming them in compressive ones that are energetically more favorable for the structure (Noordhuis and De Hosson, 1991). The general observation of low diffusivities of NGs at ambient pressure and high temperature in crystals (i.e., $\mathrm{Kr}: 1.92 \times 10^{-22} \mathrm{~m}^{2} \mathrm{~s}^{-1}$ in $\mathrm{UO}_{2}$ at $1273 \mathrm{~K}$; Michel, 2011) further supports a dissolution mechanism based on short range diffusion and lattice rearrangement. Such mechanism also operates for trace elements that tend to concentrate in defect structures in strained crystal (Piazolo et al., 2016). 


\section{Supplementary Information}

(a)

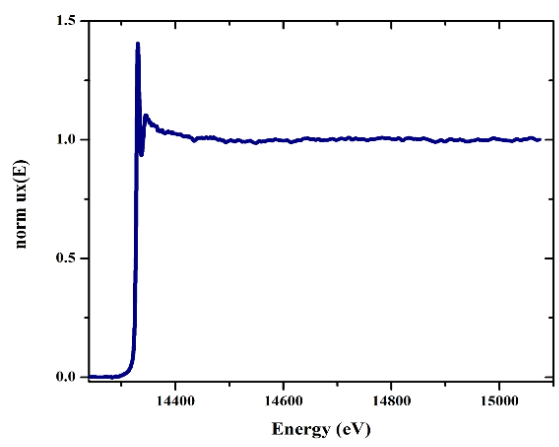

(c)

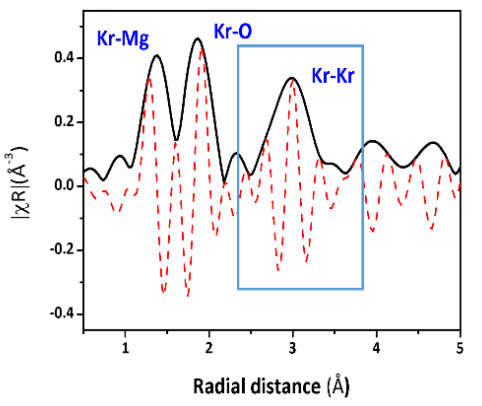

(b)

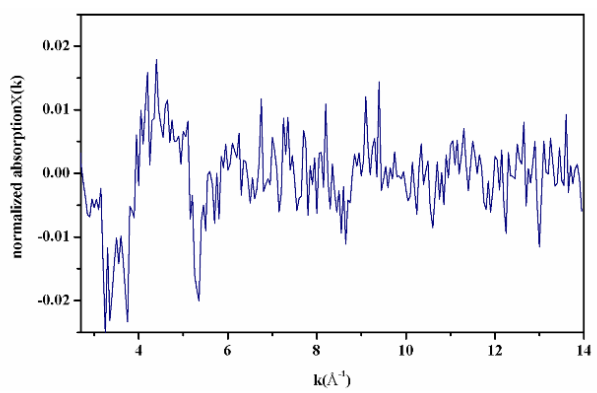

(d)

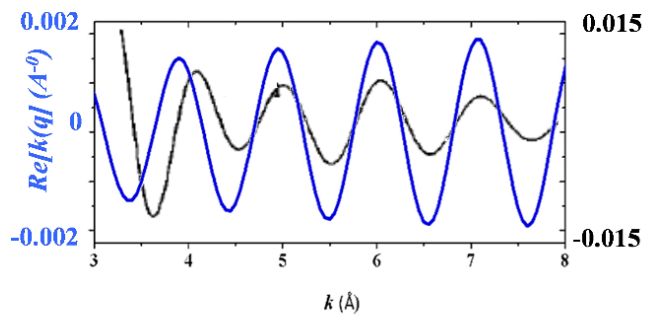

Figure S3. (a) Extended normalized K-edge X-ray absorption spectrum of Kr entrapped in quenched Fpc ( 3 wt.\% of Kr, Cell_1), (b) its extracted EXAFS function $\chi(k)$ and $(c)$ its Fourier transformation showing the mean distances of neighbouring atoms to the central absorbing $\mathrm{Kr}$ atom in $\AA$ (phase shifted). Potential neighbouring atoms and bond configurations are assigned above the three main peaks that are only based on ionic radii considerations. (d) shows the real part of the Fourier back transformation (dark blue curve) obtained from the FT region between 2.5 and $3.5 \AA$ that is indicated as blue box in (c). The back FT is compared to the theoretical Kr$\mathrm{Kr}$ single scattering path reported for solid Krypton at 8 GPa by DiCicco et al. (1996) (black curve). It is worth noting the agreement between minima and maxima positions at high $k$ and the pronounced differences in amplitude between the back FT function of this study and the theoretical $\mathrm{Kr}$-Kr single scattering path: For Kr entrapped in Fpc the amplitude of the EXAFS function is significantly smaller $( \pm 0.002)$ than the one of pure fcc $\mathrm{Kr}( \pm 0.015)$. This difference in amplitude indicates high structural disorder around Kr entrapped in Fpc. 


\section{Supplementary Information}

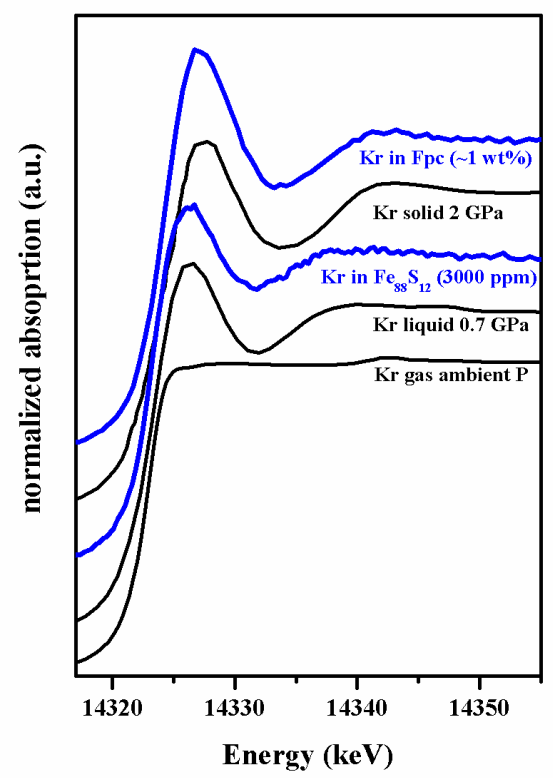

Figure S4. Selected K-edge XANES spectra of Kr entrapped in Fpc and Fe-S alloy (cell_1, 974 cell_7, blue spectra) compared to spectra of monoatomic Kr in the gas, liquid and solid state at 975 different pressures (black spectra) from DiCicco et al. (1996). Kr is in the gas state at ambient 976 pressure, liquid up to $0.85 \mathrm{GPa}$ and solidifies beyond this pressure into a fcc structure. The 977 gaseous Kr XANES spectrum is featureless after the absorption edge. The little elevation at 14340 $978 \mathrm{eV}$ is due to a double excitation process. The liquid Kr XANES spectrum is characterized by a 979 strong white line peak and a second smaller XANES peak. Compared to liquid Kr, the white line 980 position and the position of the second XANES peak of the solid pure fcc Kr spectrum are shifted 981 to higher energies. The spectra obtained of Kr retained in quenched samples is situated between 982 the liquid and solid fcc Kr in terms of white line energy position and position of the second XANES 983 peak. The slope between the first minima after the first XANES peak and the second XANES peak 984 is steeper in pure $\mathrm{Kr}$ than in entrapped $\mathrm{Kr}$. 


\section{Supplementary Information}

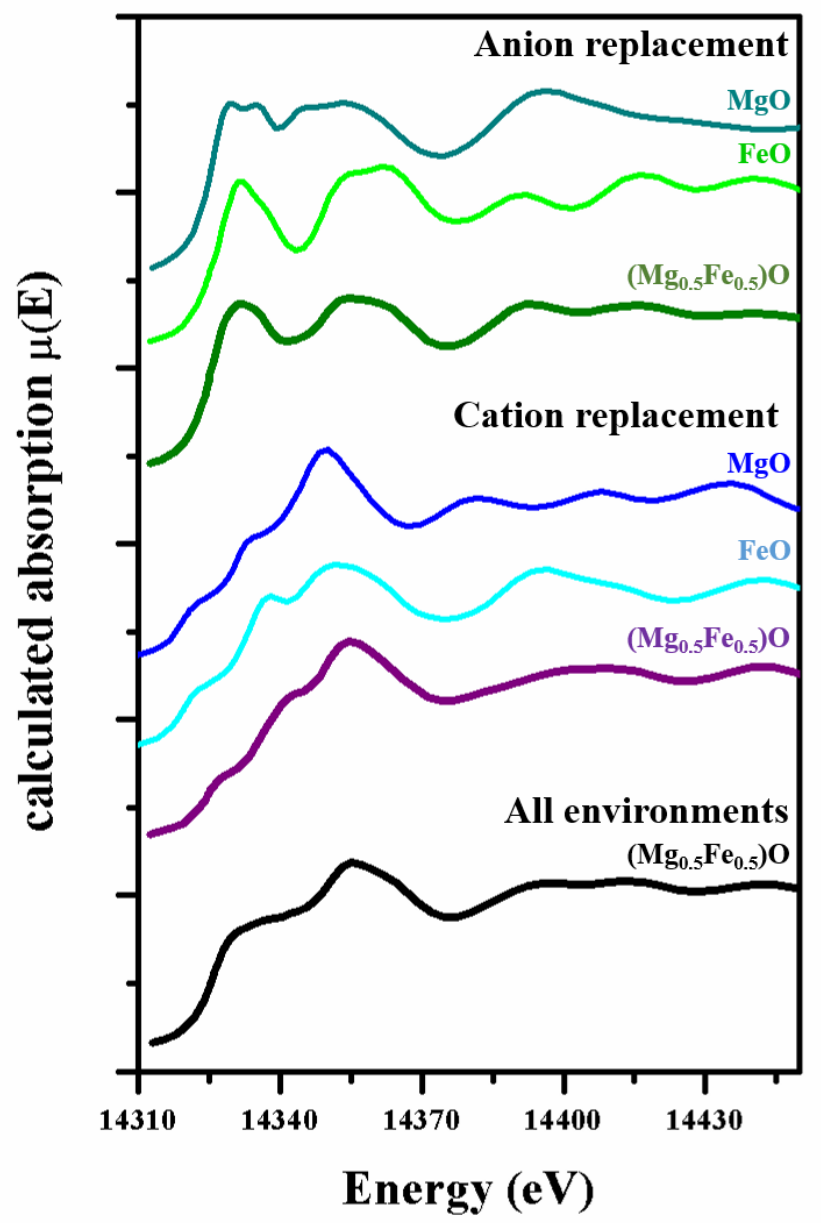

Figure S5. Calculated $\mathrm{Kr} \mathrm{K}$-edge XANES spectra for a single $\mathrm{Kr}$ atom incorporated in $\mathrm{MgO}$, $\mathrm{FeO}$ and $\mathrm{Mg}_{0.5} \mathrm{Fe}_{0.5} \mathrm{O}$. Green and blue spectra show the calculation results for Kr substituting in the anion site $\left(\mathrm{O}^{2-}\right)$ and in the cation site $\left(\mathrm{Mg}^{2+}\right.$ and $\left.\mathrm{Fe}^{2+}\right)$, respectively. The black spectrum is the sum over all calculated $\mathrm{Kr}$ environments in $\mathrm{Mg}_{0.5} \mathrm{Fe}_{0.5} \mathrm{O}$. 


\section{Supplementary Information}

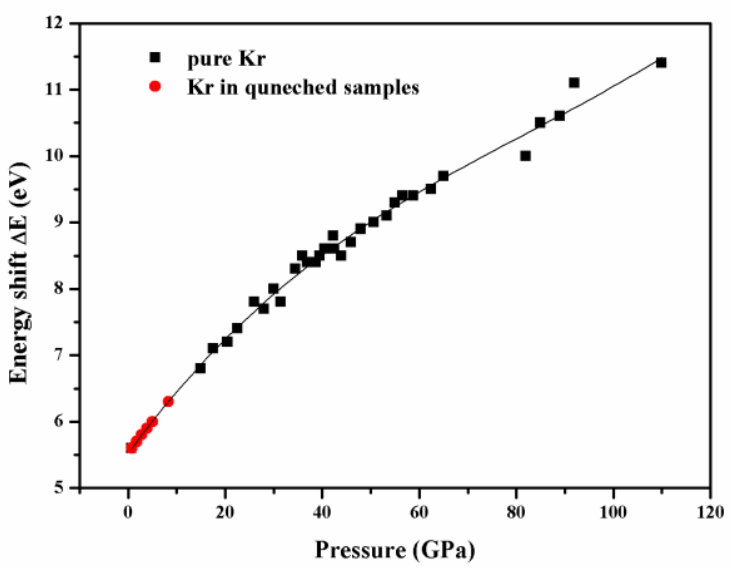

986

987

988

989

990

991

992

993

994

995

996

Figure S6. Energy shift of the first XANES peak ( $\triangle E$ in eV) of monoatomic fcc Kr (black squares) and $\mathrm{Kr}$ entrapped in quenched phases (red circles) as a function of pressure. Data for pure fcc $\mathrm{Kr}$ are taken from Rosa et al. (2018). The energy shift can directly be related to the interatomic distance between two Kr atoms as described by DiCicco et al. (1996). The black line shows a third order polynomial function fitted to the data of Rosa et al. (2018), with $\Delta E=5.525+0.09967 * P+$ $7.52 e-4 * P^{2}+3.08 e-6 * P^{3}$, where $P$ is the pressure in GPa. The individual pressures in the $K r$ clusters entrapped in quenched samples could be deduced using this fit function and the energy shift obtained from the experimental spectra of $\mathrm{Kr}$ retained in the quenched phases (red circles). 


\section{Supplementary Information}

\section{Lattice strain model approach and parameters}

We conducted lattice strain modelling following the established method of Blundy and Wood (2003) to estimate solubilities of $\mathrm{Ne}, \mathrm{Ar}, \mathrm{Kr}$ and Xe throughout the lower mantle from 25 to $120 \mathrm{GPa}$ and 1800 to $2500 \mathrm{~K}$ :

$$
c_{i}=c_{0} \times \exp \left\{\frac{-4 \pi N_{A} E_{m}\left[\frac{1}{2} r_{0}\left(r_{i}-r_{0}\right)^{2}+\frac{1}{3}\left(r_{i}-r_{0}\right)^{3}\right]}{R T}\right\}
$$

Here, $c_{i}$ is the solubility of element $i$ with radius $r_{i}, c_{0}$ is the maximal solubility of the host site, $N_{A}$ is the Avogadro's number, $E_{m}$ is the Young's modulus which provides the flexibility of the site and $r_{0}$ is the host site radius. The elasticity of the host site, $E m$ is expressed by the relation: $E m=\left(9 * K_{0} * G_{0}\right) /\left(3 * K_{0}+G_{0}\right)$.

In previous studies that developed lattice strain models for noble gases, the high $P / T$ experimental solubility data have been adjusted using ambient conditions NG radii $\left(r_{i}\right)$ (Brooker, 2003; Shcheka and Keppler, 2012). This approach results in unrealistically low values of the Young's moduli Em, that are much smaller than the values calculated from the bulk elastic moduli at the conditions of the experiment.

For example, Shcheka and Keppler (2012) obtained a fitted $E_{m}$ value of $35 \mathrm{GPa}$ for the oxygen site in $\mathrm{Bg}$, at $25 \mathrm{GPa}$ and $1800 \mathrm{~K}$. This value is close to the calculated Young's modulus of $\mathrm{Bg}$ at ambient condition $\left(E_{m}=25 \mathrm{GPa}\right)$, but differs significantly from its calculated value at the experimental conditions of the uppermost lower mantle $\left(E_{m}=440 \mathrm{GPa}\right)$. The host site at uppermost lower mantle conditions is significantly stiffer than at ambient conditions. This should be taken into account to fit and extrapolate solubility data to high $P / T$ conditions.

We intended to establish lattice strain models to predict solubilities through the mantle for the suite of NGs. Therefore, we reduced the fitting parameters in the lattice strain models to $c_{0}$ and constrained $E_{m}$ and $r_{0, i}$ to calculated values using thermoelastic and crystal-chemistry (coordination dependent atomic radii) data.

The oxygen host site radii in Fpc and $\mathrm{Bg}$ at ambient conditions were derived from Shannon (1976) by taking into account the coordination of the sites (Zhang and Zhu, 1995). In Fpc, oxygen is six-fold coordinated to cations and has an effective ionic radius of $1.4 \AA$. In Bg, oxygen is fourfold coordinated to cations but in two distinct crystallographic sites with different bond lengths, leading to an average site radius of $1.37(1) \AA$. Vacancy site radii $\left(r_{0, \mathrm{P}, \mathrm{T}}\right)$ at high $P / T$ conditions were obtained by calculating the high $P / T$ structures from the thermal equation of states reported by Mao et al. (2011) for Fpc and by Fiquet et al. (2000) for Bg (Table S2). We noted that the solubility trends of Ar, Kr and Xe reported by Shcheka and Keppler (2012) at $25 \mathrm{GPa}$ and $1800 \mathrm{~K}$ could not be reproduced with the ionic radius of oxygen in $\mathrm{Bg}$ and only with a crystal radius that is about $0.13 \AA$ smaller. We therefore employed the crystal radii obtained at high $P / T$ conditions for $\mathrm{Bg}$.

Neutral atomic effective radii of NGs at ambient conditions from Ne to Xe were evaluated using the ionic radii reported by Zhang and Zhu (1995). For Ar, $\mathrm{Kr}$ and Xe, we extrapolated the ionic radii for the [4]-fold coordination using the available data for the [6]- and [8]-fold 


\section{Supplementary Information}

coordination. The relative volume reduction of zero-charged radii at high $P / T$ conditions were obtained from those of pure NGs using the thermal equation of states listed in Table S3. The resulting radii are also listed in Table $\mathrm{S} 3$.

We employed values of $E_{m}$ that have been calculated based on bulk elastic data corresponding to the high $P / T$ conditions of the experiment using $K_{0}, G_{0}$ and their $P / T$ derivatives reported by Wang et al. (2004) (see Table S2). However, this approach does not account for the small difference in stiffness between a filled host site and a vacant site (Karato, 2016), which in general should be slightly more flexible. This may only affect NGs that exhibit large differences between their ionic radii and the ones of the host sites (i.e., $\mathrm{Ne}, \mathrm{Xe}$ in the present case). This could in turn lead to a slight underestimation of their solubilities, which is however not relevant in the present case as maximal solubilities are always used. This effect may become an important factor for solubility data obtained at high dilution levels.

Our lattice strain model approach contains only one fitting parameter that is the maximal site solubility $c_{0}$. For the oxygen site in Fpc $c_{0}$ was adjusted using the Kr solubility data obtained in the present study as anchoring points (Figure 5a). Solubilities of $\mathrm{Ar}, \mathrm{Kr}$ and $\mathrm{Xe}$ obtained at 25 $\mathrm{GPa}$ and $1800 \mathrm{~K}$ were used to fit $c_{0}$ for $\mathrm{Bg}$. Due to the absence of solubility data at higher $P / T$ conditions for NGs in $\mathrm{Bg}$, the value of $c_{0}$ obtained at $25 \mathrm{GPa}$ and $1800 \mathrm{~K}$ was subsequently employed for the $\mathrm{Bg}$ lattice strain models at 50 and $120 \mathrm{GPa}$.

The combination of $E_{P, T}, r_{0, P, T}$ and $r_{i, P, T}$ in our lattice strain model reproduces well the experimentally observed solubility trend from light to heavy NGs reported by Shcheka and Keppler (2012) (Figure 7, bold black dotted line for $\left.\mathrm{Mg}(\mathrm{Si}, \mathrm{Al}) \mathrm{O}_{3}\right)$ ). The fitted $c_{0}$ value is in good agreement with the one obtained by Shcheka and Keppler (2012). Our approach takes into account the compressibility of NGs, the type of host site and change in stiffness of a site with $P / T$. This is important because these parameters change significantly at LM conditions. We therefore conclude that, for highly compressible NGs, the present approach is appropriate and can be used for predicting NG solubilities in a host lattice site at the extreme $P / T$ conditions of the lower mantle and beyond.

Table S2. Lattice strain model input parameters used to calculate NG solubilities at high P/T conditions in Fpc and $\mathrm{Bg}$.

\begin{tabular}{|c|c|c|c|c|c|c|c|c|c|c|c|c|c|c|c|c|c|}
\hline $\begin{array}{l}\mathbf{P} \\
\mathrm{GPa}\end{array}$ & $\begin{array}{l}\mathbf{T} \\
\mathrm{K}\end{array}$ & $\begin{array}{l}\text { Fpc } \\
c_{0}\end{array}$ & $r_{0, P, T}$ & $\boldsymbol{E}_{m}$ & $\begin{array}{l}\mathbf{r i}_{\mathbf{i}}[\mathbf{6}] \\
\mathrm{He}\end{array}$ & $\mathrm{Ne}$ & $\mathrm{Ar}$ & $\mathrm{Kr}$ & $\mathrm{Xe}$ & $\begin{array}{l}\text { Bg } \\
c_{0}\end{array}$ & $\mathbf{r}_{0, \mathbf{P}, \mathbf{T}}$ & $\mathbf{E}_{\mathbf{m}}$ & $\begin{array}{l}\mathbf{r}_{\mathrm{i}}[4] \\
\mathrm{He}\end{array}$ & $\mathrm{Ne}$ & Ar & $\mathbf{K r}$ & $\mathbf{X e}$ \\
\hline 0 & 298 & 1.53 & 1.4 & 18 & 1.08 & 1.21 & 1.64 & 1.78 & 1.96 & 0.9 & 1.37 & 25 & 0.9 & 1.18 & 1.51 & 1.69 & 1.89 \\
\hline 25 & 1900 & 1.1 & 1.26 & 306 & 1.04 & 1.10 & 1.31 & 1.33 & 1.50 & 0.54 & 1.21 & 440 & 0.86 & 1.07 & 1.20 & 1.27 & 1.44 \\
\hline 50 & 1900 & 1.9 & 1.19 & 440.2 & 1.04 & 1.09 & 1.22 & 1.25 & 1.40 & 0.54 & 1.19 & 552.5 & 0.86 & 1.06 & 1.12 & 1.19 & 1.35 \\
\hline 120 & 2500 & 2.6 & 1.12 & 777.5 & 1.00 & 1.06 & 1.13 & 1.15 & 1.29 & 0.54 & 1.17 & 866.5 & 0.84 & 1.03 & 1.04 & 1.10 & 1.24 \\
\hline
\end{tabular}

Table S3. Thermo-elastic parameters for Mie-Grüneisen equation of states after Jackson and Ridgen (1996) or Dewaele et al. (2008) used to calculate NG radii at high P/T conditions.

\begin{tabular}{lllllll}
\hline & $\mathbf{V}_{\mathbf{0}}$ & $\mathbf{K}_{\mathbf{0}}$ & $\mathbf{K}^{\prime}$ & $\boldsymbol{\Theta}_{\mathbf{D}}$ & $\gamma_{\mathbf{0}}$ & $\gamma_{\mathbf{1}}$ \\
\hline $\mathrm{Ne}^{\mathrm{a}}$ & 88.98 & 1.4 & 8.03 & 75.1 & 0.97 & 2.44 \\
$\mathrm{Ar}$ & $149.8^{\mathrm{b}}$ & $2 . \mathrm{b}$ & $7.59^{\mathrm{b}}$ & $93.3^{\mathrm{c}}$ & $0.5^{\text {fixed }}$ & $2.2^{\mathrm{c}}$ \\
$\mathrm{Kr}$ & $220.61^{\mathrm{d}}$ & $1.65^{\mathrm{d}}$ & $6.7^{\mathrm{d}}$ & $79.1^{\mathrm{c}}$ & $0.5^{\text {fixed }}$ & $2.17^{\mathrm{c}}$ \\
$\mathrm{Xe}$ & $270^{\mathrm{e}}$ & $2.18^{\mathrm{e}}$ & $6.26^{\mathrm{e}}$ & $57^{\mathrm{c}}$ & $0.5^{\text {fixed }}$ & $2.36^{\mathrm{c}}$ \\
\hline
\end{tabular}

${ }^{\mathrm{a}}$ all parameters taken from Dewaele et al. (2008); ${ }^{\mathrm{b}}$ from Dewaele et al. (2018); ${ }^{\mathrm{c}}$ form Jephcoat (1998); ${ }^{\mathrm{d}}$ from Rosa et al. (2018); ${ }^{\mathrm{e}}$ from Rosa et al. (in prep.). 


\section{Supplementary Information}

\section{Formation of volatile saturated liquid/melt phase during magma ocean crystallization}

Presently, two models describing the crystallization of the magma ocean (MO) in the deep primitive Earth have been reported: (1) the classical solidification model from the bottom to the top (Solomatov and Stevenson, 1993) and (2) the more recent model that proposes the onset of solidification in the mid-mantle (Labrosse et al., 2007). For both models crystallization of LM minerals at NG saturated conditions may have occurred.

In the classical bottom-up crystallization model of Solomatov and Stevenson (1993), volatiles are incorporated in solidifying minerals in small quantities. The majority of volatiles are enriched and saturate in solution in residual liquids as solidification proceeds. Then, volatile-rich liquids rise to the surface where they form bubbles. If the size of the bubbles remains below $1 \mathrm{~mm}$, they are re-entrained in the flow of the convecting MO and resorbed at depth (Elkins-Tanton, 2008).

In the second model, buoyant crystals of the first forming solid phase (Fe-poor Bg) accumulate on the top of the LM and Fe-rich residual melt. This leads to an early chemical decoupling of the LM from the upper mantle (UM). Upon further crystallization and cooling, the basal Fe-rich melt saturates in volatiles. The early decoupling of the LM and UM is supported by geochemical observations on fissogenic Xe isotopes (Allègre et al., 1983; Pepin and Porcelli, 2006; Mukhopadhyay, 2012).

\section{NG replenishment model and considered isotopic Ne signatures therein}

In our model, we assumed that only the lower mantle has captured a solar-wind irradiated Ne isotope signature (Neon-B) after the moon-forming impact, with a ${ }^{20} \mathrm{Ne} /{ }^{22} \mathrm{Ne}$ ratio of 12.73 (Eberhart et al. 1972). We also presumed that the atmosphere has entirely lost its Neon-B signature during the moon-forming impact and that the residual atmosphere (residual Ne comprises $0.7 \%$ of primordial atmosphere) is Q-like with a ${ }^{20} \mathrm{Ne} /{ }^{22} \mathrm{Ne}$ ratio of $\sim 10.5$. In our model, the present-day atmospheric ${ }^{20} \mathrm{Ne} /{ }^{22} \mathrm{Ne}$ ratio of $\sim 9.8$ is considered as a mix of Neon-B (30.4\%), residual Q-like signature $(0.7 \%)$ and planetary component with a ${ }^{20} \mathrm{Ne} /{ }^{22} \mathrm{Ne}$ ratio of $8.5(68.9 \%)$ that was delivered during late-veneer by comets and meteorite (Marty, 2012). In our model, we supposed that the $\mathrm{Ne}$ signature of comets is Q-like, as it is for meteorites. This was proposed by Marty et al. (2008) based on measurements of refractory grains in comets. Measured Ne abundances in the comet 67P, revealed concentrations below the detection limit, showing that $\mathrm{Ne}$ was not trapped in cometary ice. In the present scenario, the solar Ne component found for MORBs and $\mathrm{CO}_{2}$ wells (Eberhart et al. 1972) may then be explained by subduction of atmospheric Ne after lower mantle outgassing. 


\section{Supplementary Information}

\section{References}

Allègre, C.J., Staudacher, T., Sarda, P., Kurz, M., 1983. Constraints on evolution of Earth's mantle from rare gas systematics. Nature 303, 762-766, DOI: https://doi.org/10.1038/303762a0.

Akawama, Y., Kawamura, H, 2004. High-pressure Raman spectroscopy of diamond anvils to 250 GPa: Method for pressure determination in the multimegabar pressure range. Journal of Appl. Phys., 96, 3748, DOI: https://doi.org/10.1063/1.1778482.

Ashcroft, N.W., Lekner, J, 1966. Structure and Resistivity of Liquid Metals. Phys. Rev. 145, 83, DOI: https://doi.org/10.1103/PhysRev.145.83

Blundy, J., Wood, B., 2003. Partitioning of trace elements between crystals and melts. Earth Planet. Sci. Lett., 210, 383-397, DOI: https://doi.org/10.1016/S0012-821X(03)00129-8.

Brooker, R.A., Du, Z., Blundy, D.J., Kelley, S.P., Allan, N.L., Wood, B.J., Chamorro, E.M., Wartho, J.A., Purton, J.A., 2003. The 'zero charge' partitioning behaviour of noble gases during mantle melting. Nature, 423, 738-741, DOI: https://doi.org/10.1038/nature01708.

Dewaele, A., Datchi, F., Loubeyre, P., Mezouar, M., 2008. High pressure-high temperature equations of states of neon and diamond. Phys. Rev. B., 77, 094106, DOI:https://doi.org/10.1103/PhysRevB.77.094106.

Dewaele, A., Torrent, M., Loubeyre P., Mezouar, M., 2008. Compression curves of transition metals in the Mbar range: Experiments and projector augmented-wave calculations. Phys. Rev. B, 78, 104102, DOI:https://doi.org/10.1103/PhysRevB.78.104102.

Dewaele, A.D., Loubeyre, P., Occelli, F., Marie, O., Mezouar, M., 2018. Toroidial diamond anvil cell for detailed measurments under extreme static pressures. Nature Com., 9, 2913, DOI: https://doi.org/10.1038/s41467-018-05294-2.

DiCicco, A., Filippono, A., Itié, J.P., Polain, A., 1996. High-pressure EXAFS measurements of solid and liquid Kr. Phys. Rev. B 54, 13, 9086-9098, DOI: https://doi.org/10.1103/physrevb.54.9086

Eberhart, P., Geiss, J., Graf, H., Groegler, N., Mendia, M.D., Moergeli, M., Schwaller, H., Stettler, A., Kraehenbuehl, U., Von Guten, H.R., 1972. Trapped solar wind noble gases in Apollo 12 lunar fines 12001 and Apollo 11 breccia 10046. Physikalisches Institute Bern, DOI: https://doi.org/10.1016/0016-7037(73)90001-X.

Elkins-Tanton, L.T, 2008. Linked magma ocean solidification and atmospheric growth for Earth and Mars. Earth Planet Sci Lett., 271, 1-4, 181-191. DOI: https://doi.org/10.1016/j.epsl.2008.03.062.

Fiquet, G., Dewaele, A., Andrault, D., Kunz, M., Le Bihan, T., 2000. Thermoelastic properties and crystal structure of $\mathrm{MgSiO}_{3}$ perovskite at lower mantle pressure and temperature conditions. Geophys. Res. Lett., 27(1), 21- 24, DOI: https://doi.org/10.1029/1999GL008397.

Giampaoli, R., Kantor, I., Mezouar, M., Boccato, S., Rosa, A.D., Torchio, R., Garbarino, G., Mathon, O. Pascarelli, S., 2018. Measurement of temperature in the laser heated diamond anvil cell: comparison between reflective and refractive optics. High Pres. Res., 250-269, DOI: https://doi.org/10.1080/08957959.2018.1480017.

Huang, H., Wu, S., Hu, X., Wang, Q., Wang, X., Fei, Y., 2013. Shock compression of Fe-FeS mixture up to 204 GPa. Geophys. Res. Letters 40, 687-691, DOI: https://doi.org/10.1002/grl.50180 


\section{Supplementary Information}

Jackson, I, Rigden, S. M., 1996. Analysis of P-V-T data: constrains on the thermoelastic properties of high pressure minerals. Physics of Earth and Plant. Int., 96, 85-112, DOI: DOI:10.1016/0031-9201(96)03143-3.

Jephcoat, A.P., 1998. Rare-gas solids in the Earth's deep interior. Nature 393, 355-358, DOI: https://doi.org/10.1038/30712.

Karato, S-I., 2016. Physical basis of trace element partitioning: A review. Am. Mineral., 101, 2577-2593, DOI: https://doi.org/10.2138/am-2016-5665.

Kantor, I., Marini, C., Mathon, O., Pascarelli, S., 2018. A laser heating facility for energydispersive X-ray absorption spectroscopy. Rev. Sci. Instrum., 89, 013111, DOI: https://doi.org/10.1063/1.5010345.

Labrosse, J.W., Hernlund, N., Coltice, A., 2007. A crystallizing dense magma ocean at the base of the Earth's mantle. Nature, 450, 866-869, DOI: https://doi.org/10.1038/nature06355.

Mao, Z., Lin, J.-F., Liu, J., Prakapenka, V.B., 2011. Thermal equation of state of lower-mantle ferropericlase across the spin crossover. Geophys. Res. Lett., 38, L23308, 1-4, DOI: https://doi.org/10.1029/2011GL049915.

Mathon, O., Beteva, A., Borrel, J., Bugnazet, D., Gatla, S., Hino, R., Kantor, I., Mairs, T., Munoz, M., Pasternak, S., Perrin, F., Pascarelli S., 2015. The time-resolved and extreme conditions XAS (TEXAS) facility at the European Synchrotron Radiation Facility: the general-purpose EXAFS bending-magnet beamline BM23. J. Synchrotron Radiat, 22(1), 1548-1554, DOI: https://doi.org/10.1107/S1600577515017786.

Martin, P.M., Vathonne, E., Carlot, G., Delorme, R., Sabathier, C., Freyss, M., Garcia, P., Bertolus, M., Glatzel, P., Proux, O., 2015. Behavior of fission gases in nuclear fuel: XAS characterization of $\mathrm{Kr}$ in $\mathrm{UO}_{2}$. J. Nucl. Mater., 466, 379-392, DOI: https://doi.org/10.1016/j.jnucmat.2015.08.019.

Marty, B., 2012. The origins and concentrations of water, carbon, nitrogen and noble gases on Earth. Earth Planet. Sci. Lett., 313-314, 56-66, DOI: https://doi.org/10.1016/j.eps1.2011.10.040.

Marty, B., Palma, R.L., Pepin, R.O., Zimmermann, L., Schlutter, D.J., Burnard, P., Westphal, A.J., 2008. Helium and Neon abundances and compositions in cometary matter. Science, 319, 7578, DOI: https://doi.org/10.1126/science.1148001.

Michel, A., 2011. Etude Du Comportement Des Gaz de Fission Dans Le Dioxyde D'uranium : Mecanismes de Diffusion. Nucleation et Grossissement de Bulles (Phd thesis), University of Caen, France.

Mukhopadhyay, S., 2012. Early differentiation and volatile accretion recorded in deep mantle neon and xenon. Nature, 486, 101-104, DOI: https://doi.org/10.1038/nature11141.

Noordhuis, J., De Hosson, J. Th.M., 1991. Fundamental and applied aspects of noble gas bubbles in steel. Edited by S.E. Donnelly and J.H. Evans. Plenum Press. New York, p. 153-165, DOI: https://doi.org/10.1007/978-1-4899-3680-6_13.

Norton, M.G, Carter, C.B., Fleischer, E., Mayer, J.W., 1992. Solid krypton in MgO. J. Mat. Res., 7, 12, DOI: https://doi.org/10.1557/JMR.1992.3171.

Pascarelli, S., Mathon, O., Mairs, T., Kantor, I., Agostini, G., Strohm, C., Pasternak, S., Perrin, F., Chapellet, P., Clavel, C. (2016) The Time-resolved and Extreme-conditions XAS (TEXAS) facility at the European Synchrotron Radiation Facility: the energy-dispersive X-ray absorption spectroscopy beamline ID24. Journal of Synchrotron Radiation 23(1), 353-68, DOI: DOI: https://doi.org/10.1107/S160057751501783X. 


\section{Supplementary Information}

Pepin, R. O., Porcelli, D., 2006. Xenon isotope systematics, giant impacts, and mantle degassing on the early Earth. Earth Planet. Sci. Lett., 250 (3-4), 470-485, DOI: https://doi.org/10.1016/j.eps1.2006.08.014.

Piazolo, S., La Fontain, A., Trimby, P., Harley, S., Yang, L., Armstrong, R., Cairney, J.M., 2016. Deformation-induced trace element redistribution in zircon revealed using atom probe tomography. Nature Com., 7, 10490, 1-7, DOI: https://doi.org/10.1038/ncomms10490.

Polian. A., Itié, J.P., Dartyge, E., Fontaine, A., Tourillon G., 1989. X-ray absorption spectroscopy on solid krypton up to 20 GPa. Physical Review B 39, 5, 3369-3373, DOI: https://doi.org/10.1103/physrevb.39.3369

Posner, E. S., Rubie, D.C., Frost, D. J., Vlcek, V., Steinle-Neumann, G., 2017. High P-T experiments and first principles calculations of the diffusion of $\mathrm{Si}$ and $\mathrm{Cr}$ in liquid iron. Geochimica Cosmochimica Acta, 203, 323-342, DOI: https://doi.org/10.1016/j.gca.2017.01.024.

Rehr, J.J., Kas, J.J., Vila, F.D., Prange, M.P., Jorissen, K., 2010. Parameter-free calculations of Xray spectra with FEFF9. Physical Chemistry Chemical Physics 7, 12, 5503. DOI: https://doi.org/10.1039/B926434E

Rosa, A.D., Garbarino, G., Briggs, R., Svitlyk, V., Morard, G., Bouhifd, M.A., Jacobs, J., Irifune, T., Mathon, O., Pascarelli, S., 2018. Effect of the fcc-hcp martensitic transition on the equation of state of solid krypton up to $140 \mathrm{GPa}$. Physical Rev. B 97, 094115, DOI: https://doi.org/10.1103/PhysRevB.97.094115.

Rosa, A.D. et al., (in prep). Martensitic transition and equation of state of Xe to $160 \mathrm{GPa}$.

Shannon, R. D., 1976. Revised Effective Ionic Radii and Systematic Studies of Interatomic Distances in Halides and Chalcogenides. Acta Crystallographica, A32, 751-767, DOI: https://doi.org/10.1107/S0567739476001551.

Shcheka, S.S., Keppler, H., 2012. The origin of the terrestrial noble-gas signature. Nature, 490, 531-534, DOI: https://doi.org/10.1038/nature11506.

Shen, G., Prakapenka, V.B., Rivers, M.L., Sutton, S.R., 2004. Structure of Liquide Iron at Pressures up to 58 GPa. Phys. Rev. B, 92, 18, 185701, 1-4, DOI: https://doi.org/10.1103/PhysRevLett.92.185701

Solomatov, V.S., Stevenson, D.J., 1993. Nonfractional crystallization of a terrestrial magma ocean. J. Geophys. Res. 98, 5391-5406, DOI: https://doi.org/10.1029/92JE02579.

Tan, Z. Budnick, J.I., Pease, D.M., Namavar, F., 1991. X-ray absorption of krypton precipitates in solid matrices. Phys. Rev. B 43, 3, 1987-1992, DOI: https://doi.org/10.1103/physrevb.43.1987.

Wang, Y., Weidner, D.J., Liebermann, R.C., Zhoa, Y., 2014. $P-V-T$ equation of state of $(\mathrm{Mg}, \mathrm{Fe}) \mathrm{SiO}_{3}$ perovskite: constraints on composition of the lower mantle. Physics Earth Planet Int., 83, 13-40, DOI: https://doi.org/10.1016/0031-9201(94)90109-0.

Zhang, Y., Zhu., X., 1995. Atomic radii of noble gas elements in condensed phases. Am. Min. 80, 670-675, DOI: https://doi.org/10.2138/am-1995-7-807. 